Prepared in cooperation with the New Jersey Pinelands Commission

\title{
Evaluating Effects of Potential Changes in Streamflow Regime on Fish and Aquatic-Invertebrate Assemblages in the New Jersey Pinelands
}

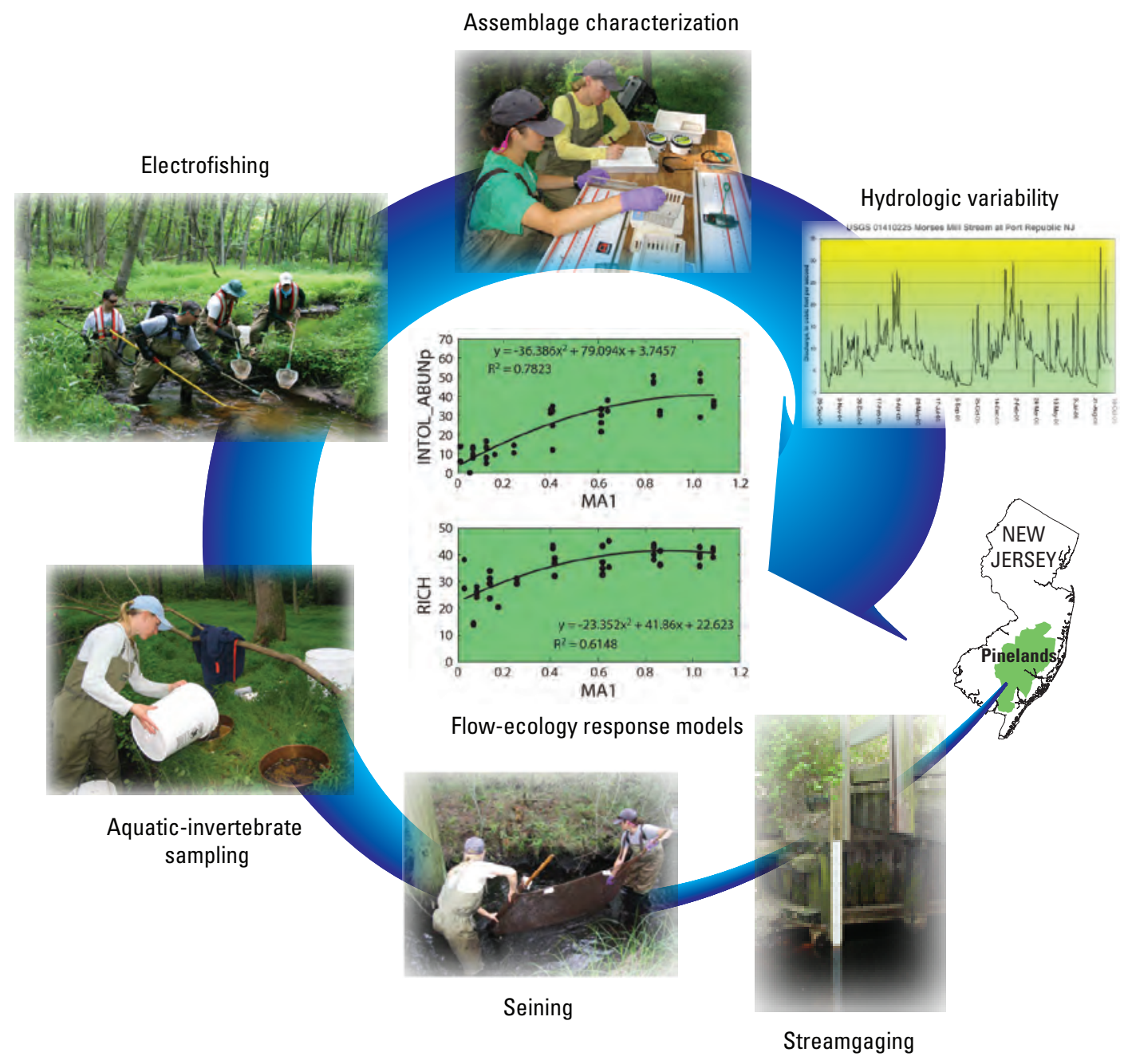

Scientific Investigations Report 2010-5079 



\section{Evaluating Effects of Potential Changes in Streamflow Regime on Fish and Aquatic-Invertebrate Assemblages in the New Jersey Pinelands}

By Jonathan G. Kennen and Melissa L. Riskin

Prepared in cooperation with the New Jersey Pinelands Commission

Scientific Investigations Report 2010-5079 


\title{
U.S. Department of the Interior \\ KEN SALAZAR, Secretary \\ U.S. Geological Survey \\ Marcia K. McNutt, Director
}

\section{U.S. Geological Survey, Reston, Virginia: 2010}

\author{
For more information on the USGS — the Federal source for science about the Earth, its natural and living resources, \\ natural hazards, and the environment, visit http://www.usgs.gov or call 1-888-ASK-USGS \\ For an overview of USGS information products, including maps, imagery, and publications, \\ visit http://www.usgs.gov/pubprod \\ To order this and other USGS information products, visit http://store.usgs.gov
}

Any use of trade, product, or firm names is for descriptive purposes only and does not imply endorsement by the U.S. Government.

Although this report is in the public domain, permission must be secured from the individual copyright owners to reproduce any copyrighted materials contained within this report.

Suggested citation:

Kennen, J.G., and Riskin, M.L., 2010, Evaluating effects of potential changes in streamflow regime on fish and aquatic-invertebrate assemblages in the New Jersey Pinelands: U.S. Geological Survey Scientific Investigations Report 2010-5079, 34 p. 


\section{Contents}

Abstract
Introduction
Purpose and Scope
Data Collection and Analysis
Site Selection
Fish-Assemblage Sampling
Aquatic-Invertebrate Assemblage Sampling
Water-Quality Monitoring
$\quad$ Habitat Assessment
$\quad$ Hethods of Validation
$\quad$ Hydrologic Attributes




\section{Figures}

1. Map showing location of Pinelands biological assessment study areas, Atlantic, Burlington, and Camden Counties, New Jersey.

2-6. Graphs showing-

2. Regression relation for fish ordination axis I scores between high- and low-flow sampling periods at 43 New Jersey Pinelands stream reaches. 11

3. Regression relation between MA1 and the observed mean annual daily flow at $15 \mathrm{New}$ Jersey Pinelands stream sites

4. Regression relation between MA1 and mean dissolved-oxygen concentration at $15 \mathrm{New}$ Jersey Pinelands stream sites

5. Invertebrate-assemblage flow-ecology response relations between the mean of the daily mean flow values for the entire flow record and (A) INTOL_ABUNp, $(B)$ EPT_CH, $(C)$ RICH, and $(D)$ ABUNTOL

6. Fish-assemblage flow-ecology response relations between the mean of the daily mean flow values for the entire flow record and $(A)$ CPSPRich,

$(B) \mathrm{MM}$, and $(C)$ R_MIGRA

\section{Tables}

1. Location and general watershed characteristics of streams used in analysis of fish and aquatic-invertebrate assemblages, New Jersey Pinelands.....

2. Taxonomic list and biogeographical classification of fish species collected in $43 \mathrm{New}$ Jersey Pinelands stream reaches

3. Relative abundance and frequency of occurrence of fish species collected at 43 New Jersey Pinelands stream reaches

4. Relative abundance and frequency of occurrence of aquatic-invertebrate taxa for samples collected at $43 \mathrm{New}$ Jersey Pinelands stream reaches

5. Median water-quality properties measured bimonthly at 15 New Jersey Pinelands stream sites.

6. Land-use, water-chemistry, and stream-reach characteristics that are significantly correlated with fish axis I scores for New Jersey Pinelands stream reaches

7. Multiple-regression model relating fish NMS axis I scores to basin characteristics for New Jersey Pinelands stream reaches

8. Reduced set of low- and annual-flow hydrologic variables that met the screening criteria and represent the hydrologic basis for developing fish-assemblage flow-ecology response models for New Jersey Pinelands stream reaches

9. Land-use, water-chemistry and stream-reach characteristics that are significantly correlated with aquatic-invertebrate axis I scores for New Jersey Pinelands stream reaches

10. Multiple-regression model relating invertebrate NMS axis I scores to basin characteristics for New Jersey Pinelands stream reaches

11. Reduced set of low- and annual-flow hydrologic variables that met the screening criteria and represent the hydrologic basis for developing invertebrateassemblage flow-ecology response models 
12. Regression relations (R-squared values) between mean monthly flow variables and the mean of all daily flows for the entire flow record (MA1) and drainage area for New Jersey Pinelands stream reaches.

13. Aquatic-invertebrate assemblage metrics that were significantly correlated with the reduced set of hydrologic measures...

14. Fish-assemblage metrics, species, and species traits that are strongly correlated with the reduced set of hydrologic measures.

\section{Conversion Factors and Datums}

\begin{tabular}{lll}
\hline \multicolumn{1}{c}{ Multiply } & By & \multicolumn{1}{c}{ To obtain } \\
\hline & Length & \\
\hline centimeter $(\mathrm{cm})$ & 0.3937 & inch (in.) \\
millimeter $(\mathrm{mm})$ & 0.03937 & inch (in.) \\
micrometer $(\mu \mathrm{m})$ & 0.00003937 & inch (in.) \\
meter $(\mathrm{m})$ & 3.281 & foot (ft) \\
kilometer $(\mathrm{km})$ & 0.6214 & mile (mi) \\
\hline & Area & acre \\
\hline square kilometer $\left(\mathrm{km}^{2}\right)$ & 247.1 & square foot $\left(\mathrm{ft}^{2}\right)$ \\
square meter $\left(\mathrm{m}^{2}\right)$ & 10.76 & square mile $\left(\mathrm{mi}^{2}\right)$ \\
square kilometer $\left(\mathrm{km}^{2}\right)$ & 0.3861 & \\
\hline & Volume & gallon (gal)
\end{tabular}

Temperature in degrees Celsius $\left({ }^{\circ} \mathrm{C}\right)$ may be converted to degrees Fahrenheit $\left({ }^{\circ} \mathrm{F}\right)$ as follows:

${ }^{\circ} \mathrm{F}=\left(1.8 x^{\circ} \mathrm{C}\right)+32$

Temperature in degrees Fahrenheit $\left({ }^{\circ} \mathrm{F}\right)$ may be converted to degrees Celsius $\left({ }^{\circ} \mathrm{C}\right)$ as follows:

${ }^{\circ} \mathrm{C}=\left({ }^{\circ} \mathrm{F}-32\right) / 1.8$

Vertical coordinate information is referenced to the North American Vertical Datum of 1988 (NAVD 88).

Horizontal coordinate information is referenced to the North American Datum of 1983 (NAD 83).

Altitude, as used in this report, refers to distance above the vertical datum.

Specific conductance is given in microsiemens per centimeter at 25 degrees Celsius $(\mu \mathrm{S} / \mathrm{cm}$ at $\left.25^{\circ} \mathrm{C}\right)$.

Concentrations of chemical constituents in water are given in either milligrams per liter (mg/L) or micrograms per liter $(\mu \mathrm{g} / \mathrm{L})$. 


\section{Abbreviations and Symbols Used in this Report}

\begin{tabular}{ll}
\hline Abbreviation & \multicolumn{1}{c}{ Description } \\
\hline ANOSIM & Analysis of Similarities \\
DO & Dissolved Oxygen \\
ELOHA & Ecological Limits of Hydrologic Alteration \\
ERHIs & Ecologically Relevant Hydrologic Indices \\
GIS & Geographic Information System \\
HIP & Hydroecological Integrity Assessment Process \\
HIT & Hydrologic Indices Tool \\
IDAS & Invertebrate Data Analysis System \\
\hline NMS & Non-metric Multidimensional Scaling \\
NWIS & National Water Information System \\
\hline PCA & Principal Components Analysis \\
\hline PRESS & Predicted Residual Sum of Squares \\
SC & Specific Conductance \\
\hline USGS & U.S. Geological Survey \\
\hline VIF & Variance Inflation Factor \\
$>>$ & Greater than \\
$<$ & Less than \\
$\geq$ & Greater than or equal to \\
$\leq$ & Less than or equal to \\
\hline
\end{tabular}




\title{
Evaluating Effects of Potential Changes in Streamflow Regime on Fish and Aquatic-Invertebrate Assemblages in the New Jersey Pinelands
}

\author{
By Jonathan G. Kennen and Melissa L. Riskin
}

\section{Abstract}

Changes in water demand associated with population growth and changes in land-use practices in the Pinelands region of southern New Jersey will have a direct effect on stream hydrology. The most pronounced and measurable hydrologic effect is likely to be flow reductions associated with increasing water extraction. Because water-supply needs will continue to grow along with population in the Pinelands area, the goal of maintaining a sustainable balance between the availability of water to protect existing aquatic assemblages while conserving the surficial aquifer for long-term support of human water use needs to be addressed.

Although many aquatic fauna have shown resilience and resistance to short-term changes in flows associated with water withdrawals, sustained effects associated with ongoing waterdevelopment processes are not well understood. In this study, the U.S. Geological Survey sampled forty-three 100-meterlong stream reaches during high- and low-flow periods across a designed hydrologic gradient ranging from small- (4.1 square kilometers (1.6 square miles)) to medium- (66.3 square kilometers (25.6 square miles)) sized Pinelands stream basins. This design, which uses basin size as a surrogate for water availability, provided an opportunity to evaluate the possible effects of potential variation in stream hydrology on fish and aquatic-invertebrate assemblage response in New Jersey Pinelands streams where future water extraction is expected based on known build-out scenarios. Multiple-regression models derived from extracted non-metric multidimensional scaling axis scores of fish and aquatic invertebrates indicate that some variability in aquatic-assemblage composition across the hydrologic gradient is associated with anthropogenic disturbance, such as urbanization, changes in stream chemistry, and concomitant changes in high-flow runoff patterns. To account for such underlying effects in the study models, any flow parameter or assemblage attribute that was found to be significantly correlated $(|r h o| \geq 0.5000)$ to known anthropogenic drivers (for example, the amount of urbanization in the basin) was eliminated from analysis. A reduced set of low- and annual-flow hydrologic variables, found to be unrelated to anthropogenic influences, was used to develop assemblageresponse models. Many linear (monotonic) and curvilinear bivariate flow-ecology response models were developed for fish and invertebrate assemblages. For example, the duration and magnitude of low-flow events were significant predictors of invertebrate-assemblage complexity (for example, invertebrate-species richness, Plecoptera richness, and Ephemeroptera abundance); however, response models between flow attributes and fish-assemblage structure were, in all cases, more poorly fit. Annual flow variability also was important, especially variability across mean minimum monthly flows and annual mean streamflow. In general, all response models followed upward or downward trends that would be expected given hydrologic changes in Pinelands streams. This study demonstrates that the structural and functional response of aquatic assemblages of the Pinelands ecosystem resulting from changes in water-use practices associated with population growth and increased water extraction may be predictable.

\section{Introduction}

The Kirkwood-Cohansey aquifer system underlies most of the New Jersey Pinelands. The interaction between groundwater and surface waters associated with this aquifer is among the most important factors influencing the structure and function of the Pinelands ecosystem. An important feature of the region is the trillions of gallons of freshwater stored within the area's streams and aquifer systems (Rhodehamel, 1970). Demand for water from the Kirkwood-Cohansey aquifer system is increasing as growth and development occur within the Pinelands and nearby metropolitan areas. The potential effects of these increased water demands are a concern for many State and municipal agencies. In addition to allowing enough water to satisfy population growth and development, State resource-management agencies must make certain that increased consumptive water use does not adversely affect the unique habitats and ecology in the Pinelands streams, wetlands, and surrounding areas. This protection of Pinelands ecology has been mandated by Public Law 2001, chapter 165, 
Evaluating Effects of Potential Changes in Streamflow Regime on Aquatic Assemblages in New Jersey

which directs named partners to "assess and prepare a report on the key hydrologic and ecological information necessary to determine how the current and future water supply needs within the Pinelands area may be met while protecting the Kirkwood-Cohansey aquifer system and while avoiding any adverse ecological impact on the Pinelands area."

Increasing demand for water and the concomitant alteration of hydrologic processes has been identified as one of the most serious threats to the ecological sustainability of aquatic ecosystems (Ward and Stanford, 1989; Poff and others, 1997; Arthington and others, 2006). This issue is exemplified by the strong linkages commonly established between modification to hydrologic processes and ecosystem function (Richter and others, 1996; Ward and Stanford, 1989; Bunn and Arthington, 2002; Townsend and others, 1997). The cumulative effects of such hydrologic alterations markedly affect the composition and structure of stream assemblages (Poff and Allan, 1995; Clausen and Biggs, 1997; Pusey and others, 2000; Konrad and Booth, 2005), most commonly by modifying natural complexity and simplifying intact systems by pushing them to a point beyond resiliency or sustainability (Baron and others, 2002). Many authors have stressed that to sustain biotic integrity, natural streamflow patterns need to be protected (Arthington and others, 1991; Sparks, 1992; Richter and others, 1996, 1997; Stanford and others, 1996). The natural flow regime paradigm (Poff and others, 1997) further emphasizes these hydroecological linkages and indicates that maintenance of inter- and intra-annual hydrologic variation is essential for sustaining the native biodiversity of aquatic ecosystems.

Water withdrawals for agricultural, municipal, and other uses have been found to reduce in-stream flows, resulting in a loss of habitat for stream biota (Postel, 2000; McKay and King, 2006). This decrease in base flow resulting from changes in groundwater and surface-water use greatly affects the suitability of a stream to sustain many types of aquatic fauna (Klein, 1979). Changes in hydrology, including annual changes in water levels, have been found to cause measurable physical and biological changes in streams (Riley, 1998). Modifications to the hydrologic regime can alter the composition, structure, and function of aquatic ecosystems through their effects on environmental and habitat characteristics, including water temperature, oxygen content, and water chemistry (Richter and others, 1996; Ward and Stanford, 1989). In addition, structural and functional components of stream assemblages are strongly influenced by temporal variation in flow processes (Biggs and others, 2005), and many aquatic species have evolved specific life-history traits that allow them to take advantage of various characteristics of the flow regime (Poff and others, 1997; Vieira and others, 2006; Poff and others, 2006). Flow components including low flows (base flows), annual flow pulses, seasonality of flows, and annual variability provide the conditions necessary to support natural-assemblage complexity (Stanford and others, 1996; Poff and others, 1997; Richter and others, 1997; Mathews, 2005). Alterations in the timing, duration, and magnitude of many of these flow processes can substantially affect sensitive aquatic fauna that embody less resilient or robust life histories. For example, flow is an important factor in the life histories of fish, as critical life events such as spawning behavior, larval survival, growth patterns, and recruitment are directly linked to natural annual patterns in the flow regime (Humphries and others, 1999). Reduced flow commonly leads to decreases in dissolved-oxygen content, which is critical to larval fish survival (Robinson and others, 2004). Many fish species display a preference for particular types of habitat, such as riffles, pools, or backwater areas, all of which are affected by flow (Pusey and others, 1993). The richness of species typically increases as instream habitat complexity increases, with depth, velocity, and cover being the most important variables (Pusey and others, 1995). Associations between fish and their habitats are influenced by flow variability at a range of spatial scales. Flow variability and habitat structure can have a clear influence on fish assemblages within a drainage network as well as on a regional scale. For example, changes in flow variability, such as those resulting from surface-flow dewatering and lowered groundwater levels, have been linked to losses of important instream habitat (for example, riffles and woody debris) that can affect fish, invertebrate, and native mussel species distribution. Studies in streams in the eastern United States (for example, Armstrong and others, 2001), identified fluvial-dependent fish species as being sensitive to hydrologic stress associated with reduced streamflow; abundances of habitat generalists, in contrast, have been found to increase (Roy and others, 2005). Prolonged periods of low and reduced-magnitude flows also can reduce habitat availability and quality, ultimately altering trophic dynamics (Power and others, 1996; Poff and others, 1997). In addition, non-native and invasive species are commonly favored by alteration of the flow regime. Long-term success of an invading fish species is much more likely in a permanently altered aquatic system than in a lightly disturbed system (Moyle and Light, 1996). The most successful invaders will be those that are adapted to the modified flow regime.

Fluctuations in base flow and repeated exposure of areas along stream margins have been shown to result in slow recovery and decreased production of aquatic-invertebrate assemblages (Perry and Perry, 1986; Blinn and others, 1995). Stream velocity, substrate complexity, and dissolved-oxygen concentration are among the most important factors influencing the distribution and abundance of aquatic invertebrates. These three factors are highly interrelated, with stream velocity partly determining both sediment type and dissolved-oxygen levels (Allan, 1995). Rivers with unstable substrates tend to be characterized by low species diversity and abundance, and the existing biota typically have life-history or behavioral characteristics that reflect frequently disturbed environments. Maitland (1994) reported greater reductions in the fauna of sandy compared to stony areas during flooding, apparently as a result of the reduced stability of the sandy-bottomed substrate. The nature of the effects of changing water levels and alterations in natural variability on aquatic insect communities depends on the extent, duration, and rapidity of the fluctuations, the season 
during which drawdown occurs, the trophic status of the water body, and the climate of the region. Rapid lowering of the water level may strand large numbers of benthic organisms. Immobile pupae of aquatic insects are especially vulnerable to changes in water level. Some aquatic insects are dependent on natural water-level fluctuations for the completion of their life cycles; without these changes, various stages of development can be prolonged for a year or more (Ward, 1992).

In this study, the U.S. Geological Survey (USGS) evaluated fish and aquatic-invertebrate assemblages in streams that are likely to experience changes in streamflow regime in the New Jersey Pinelands and postulated that variation in streamflow characteristics (that is, the variation in at least one of the primary components of streamflow-magnitude, frequency, duration, timing, and rate of change) associated with increased water extraction would explain a significant portion of the variation in assemblage complexity along a hydrologic gradient. In order to test this hypothesis, variation in streamflow processes was evaluated by (1) deriving simulated hydrographs for all study sites based on data records from continuous gaging stations, (2) identifying a subset of significant hydrologic variables (for example, duration, magnitude, frequency, and seasonality of low- and annual-flow events), (3) evaluating the linkages between hydrologic indicators and variation in fish and aquatic-invertebrate assemblage structure and function in the absence of underlying anthropogenic disturbance, and (4) developing a set of predictive linear and nonlinear flow-ecology response models that identify the most significant hydrologic attributes that, if modified through changes in water-use practices, most reliably account for variation in the richness and composition of fish and invertebrate assemblages along a hydrologic-response profile.

\section{Purpose and Scope}

This report describes the development of flow-ecology response models that can be used to predict the potential effects of streamflow reductions on fish and aquatic-invertebrate assemblages in New Jersey Pinelands streams. The relevance of the models to the management of the flow modifications is discussed.

\section{Description of Study Area}

The New Jersey Pinelands is a 1.1-million-acre natural reserve in southern New Jersey that has diverse land use, including recreational, agricultural, residential, and commercial (State of New Jersey, 2007). The Pinelands lies within the Northern Atlantic Coastal Plain physiographic province and is underlain by the Kirkwood-Cohansey aquifer system (fig. 1). The Kirkwood-Cohansey aquifer system is the uppermost hydrogeologic unit of a wedge-shaped sequence of Coastal Plain sediments. The aquifer is composed of sand and gravel aquifers separated by silt and clay confining layers that thicken and dip from the western limit of the Coastal Plain at the Fall
Line to the southeast, reaching a thickness of more than 1,981 $\mathrm{m}(6,500 \mathrm{ft})$ at Cape May, New Jersey (Farlekas and others, 1976; Zapecza, 1989). The upland vegetation of the Pine Barrens is dominated by pitch pine and a variety of oaks. The wetland communities occupy about 25 percent of the region and are dominated by pitch pine, Atlantic white cedar, and red maple. Surface waters are fed primarily from groundwater discharge (Rhodehamel, 1979), and typically are nutrientpoor, stained brown by humic materials and iron, and acidic (Morgan, 1984).

This study focused primarily on three basins in the Kirkwood-Cohansey aquifer system: the Batsto River, Pump Branch/Albertson Brook, and Morses Mill Stream Basins. Also included in the study were two other basins-the Bass River and Mt. Misery Brook Basins (fig. 1). The sites in these study basins represent a range in watershed land use consistent with existing development and agricultural practices within the Pinelands (table 1).

\section{Data Collection and Analysis}

This study was designed to apply fish and aquaticinvertebrate sampling techniques appropriate for Atlantic coastal streams to the development of a series of flow-ecology response models relating variation in assemblage structure and function to variation in streamflow regimes as described in the Kirkwood-Cohansey Project work plan, available at http://www.state.nj.us/pinelands/science/kirkwood/.

\section{Site Selection}

Fifteen stream sites representing a range of discharge regimes and basin areas less than $70 \mathrm{~km}^{2}\left(27 \mathrm{mi}^{2}\right)$ in size were selected in the Batsto River, Morses Mill Stream, Bass River, Mt. Misery Brook, and Pump Branch/Albertson Brook Basins (fig. 1). At all but one of the eight sites selected in the Batsto River Basin, four 100-m-long sampling reaches (only two at Batsto River near Tabernacle because of similarity in stream properties), representing different habitats and characterized by differing flow and velocity regimes, were selected. At seven stream sites in the Morses Mill Stream, Bass River, and Pump Branch/Albertson Brook Basins, two 100-m-long reaches were selected; at the North Branch Mt. Misery Brook site, however, only one suitable $100-\mathrm{m}$-long reach was identified, for a total of 43 reaches. This hydrologic gradient (that is, varying stream velocity, discharge, and basin area) was specifically incorporated into this study because of its influence on sediment size, temperature, dissolved-oxygen content, and aquatic-vegetation abundance, all of which directly influence habitat diversity, complexity, and distribution of aquatic assemblages. All 43 study reaches (table 1) were sampled during low- and high-flow periods to account for variability in assemblage structure and function. 


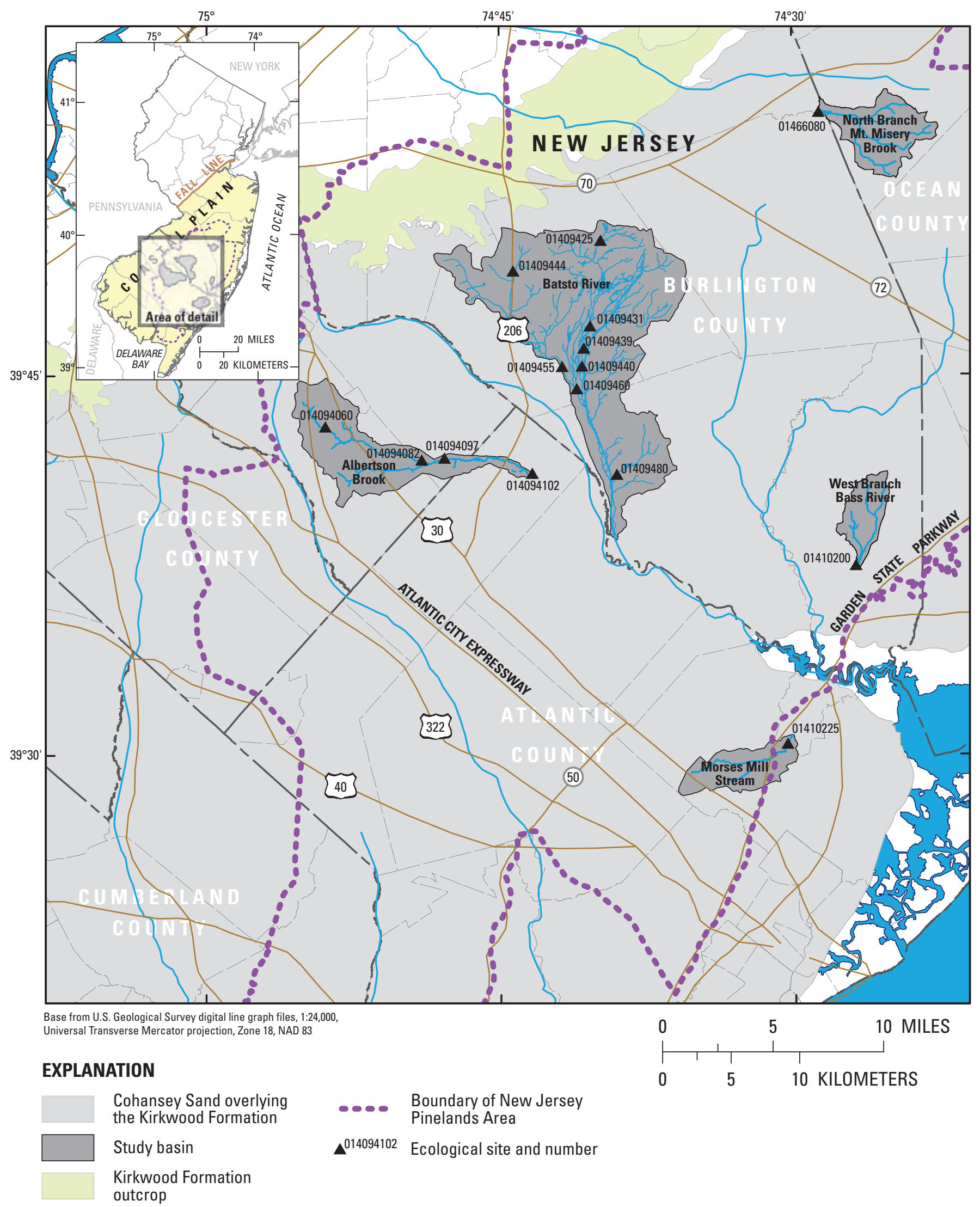

Figure 1. Location of Pinelands biological assessment study areas, Atlantic, Burlington, and Camden Counties, New Jersey. 


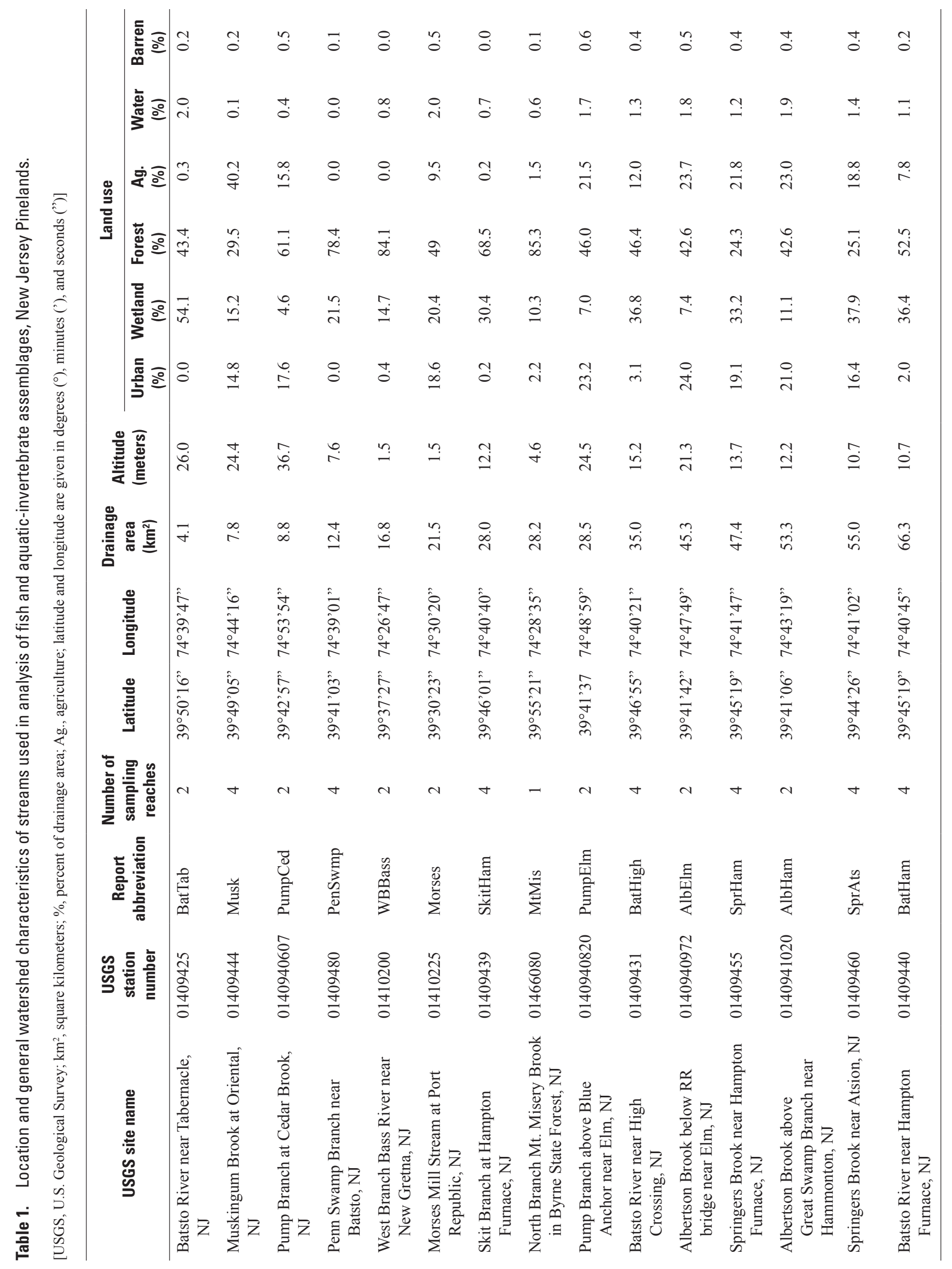




\section{Fish-Assemblage Sampling}

All fish-assemblage sampling was conducted in 2005 during high-flow (June) and low-flow (September-October) periods at all forty-three 100-m-long reaches in the Batsto River, Morses Mill Stream, Bass River, Mt. Misery Brook, and Pump Branch/Albertson Brook Basins. In an effort to minimize seasonal variations in flow among sites, all fish surveys were performed within a short time period $(<5$ weeks $)$.

Fish surveys were performed in an upstream direction following the protocols outlined by Moulton and others (2002), using nylon seines and a Smithroot ${ }^{\circledR}$ Model LR-24 pulsed DC backpack electrofishing unit. Voltage output typically ranged from 150-800 at 30 hertz, depending on specific conductance. Specific conductance (ability of water to carry an electrical current) was measured prior to electrofishing to determine the appropriate output voltage for effective fish capture (Reynolds, 1996). Some interior Pinelands streams have, on average, very low specific conductance (for example, Skit Branch at Hampton Furnace (01409439), $33 \mu \mathrm{S} / \mathrm{cm}$ ) and require more power to effectively capture fish, whereas streams nearer the periphery of the Pinelands have higher specific conductance (for example, Muskingum Brook at Oriental (01409444), 188 $\mu \mathrm{S} / \mathrm{cm}$ ) and typically require less power. Some modifications to the Moulton and others (2002) protocols were implemented for proper fish capture in Pinelands streams typically stained brown by humic materials. In some instances, these modifications included setting up blocking seines at the upstream and (or) downstream ends of a stream reach to prevent emigration during sampling. This procedure is necessary in some Coastal Plain streams where no natural barriers (for example, riffles, bedrock terraces, or stone dams) can be established. In addition, a seine was positioned downstream from the electrofishing unit to capture fish that did not exhibit galvanotaxis (that is, fish that avoid rather than swim voluntarily toward the anode) or any cryptically colored fish that eluded initial capture (for example, pirate perch and yellow bullhead). During the sampling process, stunned fish were netted immediately (6.35-mm mesh) and placed in aerated holding containers. All major and minor habitats (for example, riffles, runs, pools, debris dams, back eddies, side channels, undercut banks, vegetation mats) in the stream reach were sampled thoroughly. All fish were identified to species, counted, weighed (grams), measured (millimeters total length), examined externally for disease and anomalies, recorded, and then returned to the stream reach.

\section{Aquatic-Invertebrate Assemblage Sampling}

Multihabitat aquatic-invertebrate assemblage samples were collected within the same 100-m-long stream reaches that were sampled for fish following the protocols outlined by the Mid-Atlantic Coastal Stream Workgroup (U.S. Environmental Protection Agency, 1997), which were specifically selected to effectively sample aquatic invertebrates in mid-Atlantic
Coastal Plain streams (Maxted and others, 2000). The 30 study reaches in the Batsto River Basin were sampled in 2004 under high-flow (June-July) and low-flow (October-November) conditions and the 13 study reaches in the Morses Mill Stream, Bass River, Mt. Misery Brook, and Pump Branch/Albertson Brook Basins were sampled under both high-flow (May-June) and low-flow (October-November) conditions during 2005.

At each of the 100-m-long reaches, 20 D-net jab samples, distributed proportionally throughout targeted habitats, including undercut banks, woody snags, submerged macrophytes, organic debris, sand, and muck, were collected. In addition to the 20 jab samples, five pieces of woody debris were collected at each of the reaches. The woody debris collected were submerged sections of wood (branch or log) having on average a minimum diameter of $1 \mathrm{~cm}$ and colonized by aquatic organisms. They were processed separately, and then composited with the 20 discrete D-net samples. These composites provide a fully integrated and representative aquatic-invertebrate sample for each 100-m-long reach. Once the sample was collected, large organic and inorganic material was inspected, rinsed, and removed. All materials in the samples, including small debris and loose material, were elutriated and sieved through a standard brass $500-\mu \mathrm{m}$ mesh sieve (Moulton and others, 2002). The remaining material was placed into a 1-L container, preserved with 95-percent ethyl alcohol, and shipped to EcoAnalysts, Inc., in Moscow, Idaho, for processing.

In the laboratory, samples were sieved and rinsed with tap water to remove fine sediments and excess preservative. A quantitative fixed-count processing method was used to identify and estimate the abundance of each taxon sorted in the samples. Samples were placed on a gridded Caton tray (a 250- $\mu \mathrm{m}$ mesh, rectangular, stainless steel, gridded sieve that nests in a plastic tray) and distributed homogeneously throughout the tray. Sections of the gridded Caton tray $(5.1 \mathrm{~cm} \times 5.1 \mathrm{~cm})$ were chosen randomly and a 300-organism subsample was removed systematically, sorted into gross taxonomic categories (for example, Chironomidae, Oligochaeta, and all other organisms), and placed in glass vials containing 70-percent ethanol. This approach is similar to the methods described by Barbour and others (1999) and Plafkin and others (1989) and meets the quality-assurance/quality-control elements important for accurate evaluation of taxonomic results used in biological assessments (Stribling and others, 2003). Aquatic invertebrates were identified to the lowest possible taxonomic level, enumerated, and entered in a digital database for further analysis.

\section{Water-Quality Monitoring}

Water-quality samples were collected at or near continuous-record and staff gages colocated at all fish- and invertebrate-sampling reaches using a YSI 6920 multiparameter meter from July 2004 through August 2006. Water-temperature, air-temperature, $\mathrm{pH}$, specific-conductance (SC), and dissolvedoxygen (DO) measurements were made bimonthly throughout 
the duration of the study; however, degraded road conditions (that is, snow and ice covering the roads) during the winter months occasionally prevented access to some sampling sites (twice at BatHam and once at AlbHam). In addition, waterquality measurements were made prior to all fish- and invertebrate-sampling events.

\section{Habitat Assessment}

Instream habitat was assessed following a modification of the habitat-sampling protocol outlined by Fitzpatrick and others (1998). Measurements of instream habitat were made at each 100-m-long sampling reach, which was divided into 25-m sections, and habitat characteristics were assessed across each of these five transects perpendicular to streamflow. Along each transect, channel features such as wetted width, water-column velocity, altitude, substrate size, dominant substrate, geomorphic channel unit (run, riffle, pool), riparian and canopy conditions, streambank angle, height, and stability, and canopy opening and riparian width and stability were recorded. At each transect, three point-velocity measurements were made using a pygmy or Price AA standard flow meter (depending on depth). Instantaneous stream discharge (in cubic feet per second) was acquired from a colocated USGS streamflow-gaging station or assessed indirectly from staff gages installed at the sampling reaches. Stream width, depth, and water-surface altitude also were measured. Canopy openings were measured through the use of a handheld clinometer. Angular measurements were made from mid channel to the tallest objects to the left and right of each transect. The left and right angles were summed and subtracted from 180 degrees to acquire the open-canopy angle.

Instream vegetation was measured along transects established perpendicular to flow at 5-m intervals using the lineintercept method. Transects begin and end at edge-of-water. At each transect, the length of contiguous cover of individual plant species, woody cover, and areas that did not have woody cover or plant cover was recorded. Submerged woody cover consisted of branches or logs that were $\geq 10 \mathrm{~cm}$ in diameter. In some instances, instream vegetation could not be sampled as a result of deep water (three transects total-the uppermost transect on Muskingum Brook, reach 3, and the two uppermost transects on Batsto River near Hampton Furnace, reach $3)$. Percentage cover was calculated by dividing the length of cover for a species at a transect by the total length of the transect. Tree-canopy cover was measured with a spherical densiometer in the center of each $25-\mathrm{m}$ section. Four measurements were made in the center of each $25-\mathrm{m}$ section and averaged to obtain a final tree-canopy cover value.

\section{Hydrologic Assessment}

Streamflow characteristics such as annual and seasonal high and low flows, monthly flows, and flow variability are essential for understanding and predicting the effect of alterations in the natural flow regime on stream biota (Olden and Poff, 2003). Therefore, the development of hydrographs and measurement of stream velocity at all sampling sites was vital to meeting the objectives of this study. The following sections describe the methods used to obtain the flow information necessary for developing the hydroecological models presented in this report.

\section{Cross-Section Calculations}

Velocity measurements were made at all of the ecological transects using a pygmy or Price AA standard flow meter (depending on depth) at three points across each transect-the thalweg and two points on either side of the thalweg midway to the edge of water (see Fitzpatrick and others, 1998). Using these three velocity measurements, water depth, and bankheight measurements, a simple model was developed to calculate the area of water available at any transect for a specific gage height. Water area was calculated as a rectangle centered over each depth measurement. Water level was lowered by subtracting a predetermined incremental drop from bankfull depth to near base flow. Bankfull depth is equal to the height of the staff at the time of habitat assessment plus the measured bank height. The width is then recalculated along the edges using proportional triangles. Given that velocity (meters per second) is equal to the discharge (cubic meters per second) divided by the area (square meters), velocity could be calculated using the area from the simple model and discharge from the USGS stage-discharge-relation rating tables (for a given staff-gage height). Velocities were then calculated for each of the five transects within a reach and averaged across the length of the stream reach to characterize the velocity profile for each sampling reach.

\section{Methods of Validation}

Several methods of validation were used to ensure the model was an accurate means of characterizing the variation in velocity throughout the sampling reaches. The model needed to be validated because USGS guidelines dictate that the ideal standard measurement is one in which no partial stream section contains more than 5 percent of the total discharge and, on average, that has 25 to 30 sections measured across a stream transect to accurately determine area, velocity, and discharge (Buchanan and Somers, 1969). Because that level of detail was not feasible for all of the 43 sampling reaches in this study, it was necessary to determine whether three depth and velocity measurements at a given transect were adequate to characterize the velocity profile of a stream reach.

First, flow calculations based on the simple model were validated against the "complete" standard USGS discharge measurements that were made at a gage height when flow conditions were similar to the flow conditions when habitat assessments were made. Standard USGS discharge measurements were made many times throughout the study 
(approximately nine times per year) to establish a gage rating as part of the hydrologic component of the study (White and others, 2006). The comparability between the simple model flow estimates and those derived from a standard USGS approach for the subset of data points compared was within an acceptable 5 percent of the more intensive standard measurement values. The area values calculated from the standard measurement also were compared to the area values from the three measured points used in the model; these two measurements also were highly comparable and rarely differed by more than 3 percent. Model output also was directly validated against velocities calculated using discharges from the USGS rating tables and areas from the model using the actual instantaneous velocities measured in the field during the habitat assessments. These relations also were highly comparable. Modeled discharge and velocities based on the transect approach used in this study consistently came within a small percentage (about 5 percent) of the values calculated with the more intense standard cross-sectional assessment method. Subsequently, the simple modeling method was applied to all sites and transects in the study.

\section{Hydrologic Attributes}

Instantaneous-streamflow measurements were made approximately every 6 weeks at all of the ecological sampling sites from spring 2004 through fall 2006. Typically, 9 to 12 flow measurements provide enough information to establish a significant regression between flow conditions at a continuous-record index gaging station and those at a site with no continuous record of streamflow-only instantaneousflow measurements (that is, a partial-record station) (Watson and others, 2005). Maintenance of Variance Extension Type 1 (MOVE1) method of analysis (Hirsch, 1982) uses daily mean flows from at least three proximal continuous-record index gaging stations either on the same stream or at nearby streams with similar basin characteristics and then regresses them against flows measured at a partial-record station (in this study, all ecological sampling sites with installed staff gages). Continuous-record index gaging stations are those with a minimum of 20 years of continuous discharge record (Watson and others, 2005).

MOVE1 generates regression equations that summarize the relation between the daily mean flows at a set of proximal USGS index sites and the partial-record sites of interest. For this study, the index site for which flows correlated best with those at a specific ecological sampling site was chosen based on the highest average regression R-squared value (all R-squared values used were $>0.98$ ). Mullica River near Batsto, NJ (01409400), was the index station selected for all ecological sampling sites in the Batsto River Basin using the period of record 1957-2006. Great Egg Harbor River at Folsom, NJ (01411000), was used for the Pump Branch/Albertson Brook Basin, Morses Mill Stream, North Branch Mt. Misery Brook, and West Branch Bass River Basin ecological sampling sites using the period of record 1925-2006. Using these index stations and the equations derived from MOVE1, hydrographs were generated for all of the ecological sampling sites for the study period of record, 2004-06.

\section{Hydroecological Integrity Assessment Process}

The Hydroecological Integrity Assessment Process (HIP) software is used to relate alterations in hydrologic processes as a result of water depletion or hydrologic alteration scenarios to aquatic-assemblage response (Kennen and others, 2007). The software generates a series of ecologically relevant hydrologic indices (ERHIs) to help characterize and classify streamflow regimes that are thought to be important in shaping ecological processes in streams (Olden and Poff, 2003; Henriksen and others, 2006; Kennen and others, 2007). The HIP software uses USGS daily mean and peak-flow discharges from the National Water Information System (NWIS) databases (available at http://waterdata.usgs.gov/nwis/sw). The Hydrologic Index Tool (HIT), a stand-alone program that is part of the HIP suite of software, generates 171 hydrologic indices by using daily mean and peak-flow discharge data (if they are available). If peak-flow data are not available, then eight HIT indices (that is, FH11, DH22, DH23, DH24, TA3, TH3, TL3, and TL4; see Kennen and others (2007) for definitions of all 171 indices) are not calculated. The 171 indices are based on the five primary components of the flow regime-magnitude, frequency, duration, timing, and rate of change (Poff and others, 1997). Daily hydrologic data for all of the ecological sampling sites from May 2004 through May 2006 were run through HIT and a suite of ERHIs was generated. Peak-flow data were not available for the sampling sites (because the daily mean values were generated using a regression equation), so only 163 indices were calculated.

\section{Analytical Methods}

Variation in hydrologic, land-use, and environmental attributes and fish and aquatic-invertebrate assemblage structure and function was assessed using a combination of correlation, regression, and multivariate analyses to identify potential linkages among these characteristics and to determine the most statistically significant hydrologic attributes driving assemblage response. Fish and aquatic-invertebrate assemblages were analyzed on the basis of species composition. Species composition was based on the total abundance of selected taxa. Aquatic-invertebrate site by species matrices were censured by eliminating rare species that accounted for less than 0.01 percent of overall abundance and that were present in less than 2 percent of the samples by using the Invertebrate Data Analysis System (IDAS) (Cuffney, 2003; Cuffney and others, 2007). Fish matrices were not censured as all taxa were readily identified to species in the field and no rare taxa were found. IDAS was also used to derive many aquatic-invertebrate structural and functional metrics for use 
in univariate and multivariate analyses and the development of flow-ecology response relations (Arthington and others, 2006).

Non-metric multidimensional scaling (NMS) was used to evaluate variation in fish and aquatic-invertebrate assemblage structure and function across the hydrologic gradient. Fish and aquatic-invertebrate data were first standardized by total abundance and square-root transformed. The distance measure used was Bray Curtis, and NMS procedures were performed using PRIMER v6 software (Clarke and Warwick, 2001; Clarke and Gorley, 2006). The NMS analysis was used primarily to explore whether environmental attributes other than hydrology were accounting for a proportion of the variability in the distribution of fish and invertebrate taxa in ordination space (for example, Roy and others, 2003; Walters and others, 2003; Kennen and others, 2005). It was also essential to the modelbuilding process that hydrologic attributes and assemblage metrics that were directly responding to anthropogenic alteration rather than to changes in annual streamflow processes be removed. This procedure was accomplished by deriving MLR models based on the extracted synthetic factors (NMS axis I scores) for fish and invertebrate assemblages and determining whether a significant amount of the variance across the hydrologic gradient was accounted for by known indicators of anthropogenic disturbance (that is, the percentage of urban and agricultural land in a basin, $\mathrm{pH}$, and specific conductance) (Zampella and Bunnell, 1998), and then by running a series of Spearman correlations using a statistically reduced subset of significant hydrologic variables against indicators of anthropogenic degradation. Any hydrologic attribute or assemblage metric that was found to be significantly correlated $(|r h o| \geq 0.5000)$ with the percent of basin urbanization or agriculture or indicators of diminished water quality (that is, high $\mathrm{pH}$ or $\mathrm{SC}$ ) was eliminated from further analysis.

A total of 448 environmental variables (that is, hydrologic, landscape, water-quality, and physical variables associated with each stream reach) was evaluated for this study. Principal components analysis (PCA) (SAS Institute Inc., 1989) in combination with collinearity assessment was used to isolate a subset of variables for use in response models that accounted for the greatest proportion of variance while minimizing redundancy (for example, Olden and Poff, 2003). Distributions of all variables were evaluated for normality and transformed when necessary. We conducted PCA on the correlation matrix and evaluated the significance of principal components using the broken stick method (Jackson, 1993; McCune and Grace, 2002). By using the correlation matrix, we ensured that all the environmental variables contributed equally to the PCA and that the contributions were scaleindependent (Legendre and Legendre, 1998). Loadings of the environmental variables on each significant principal component were used to identify variables that extracted dominant patterns of variation. A Spearman rank correlation matrix (SAS Institute Inc., 1989) of the reduced set of environmental variables was examined to eliminate any remaining redundant variables with a Spearman's rho $>0.75$. This conservative data-reduction approach helped avoid the common pitfalls associated with establishing significant $(p \leq 0.05)$ correlations among a large suite of environmental variables simply by chance and introducing interdependencies among multiple explanatory variables (Van Sickle, 2003; King and others, 2005).

We used correlation, linear, and nonlinear (for example, polynomial) regression analysis to relate the reduced set of hydrologic variables to fish and aquatic-invertebrate assemblage response. Ordination results were incorporated into MLR analysis by using the NMS axis I scores as the response variable. Stepwise MLR analysis using forward selection and backward elimination procedures was then used to identify the minimum set of explanatory variables needed to account for the observed variation in the response variables - that is, MLR models were constructed that describe the relation between environmental variables and the distribution of fish and invertebrate assemblages along the hydrologic gradient. Conservative entry and removal criteria $(p=0.05)$ were used to ensure high predictive power. By using multiple explanatory variables to estimate values of a response variable, errors in prediction were limited while still accounting for a large proportion of the variance in the response variable. In addition, this approach provides diagnostic tools that allow us to explicitly account for the dependencies between multiple candidate explanatory variables (Van Sickle, 2003). In combination, the data-reduction approach used in this study helped reduce the number of environmental and assemblage metric variables available for modeling from 448 to 45 .

Best-fit MLR models were derived from the reduced set of explanatory variables. The comparative performance of MLR models was evaluated using the coefficient of determination (R-squared value), which is the percentage of the variability of the dependent variable that is explained by the variation of the independent variables. The $\mathrm{R}$-squared value ranges from 0 to 1 , with 1 being a perfect fit; most MLR modeling procedures attempt to maximize this value. Models also were evaluated on the basis of Variance Inflation Factor (VIF) of the component variables; a higher VIF indicates that a variable is more closely related to one or more other variables in the model than to the model itself. A standard VIF cut-off criterion of 10 was used for evaluating whether there was any undue influence of one independent variable on another; however, this value is considered somewhat arbitrary as there are no formal criteria for determining the magnitude at which an inflation factor actually results in poorly estimated regression coefficients (SAS Institute Inc., 1991). MLR models were validated using an n-1 (that is, "leave-one-out") cross-validation approach using the predicted residual sum of squares (PRESS) procedure (Weisberg, 1985). At each iteration a different observation is omitted from calibration to generate a predicted value. At the end of this process, a series of $\mathrm{n}$ predictions is assembled from the deleted observations and is compared with the observed values to produce the PRESS statistic, which is a validation statistic of model accuracy and error. As a validation technique, PRESS tests how well the current model would predict each of the points in 
the dataset (in turn) if they were not included in the regression. Low values of PRESS generally indicate that the model is not overly sensitive to any single data point. PRESS is considered comparable to tests of independent validation (Kozak and Kozak, 2003) and is often recommended over the split-sample validation approach, which has been shown to be less reliable, commonly providing highly biased estimates of prediction accuracy and performance (Olden and Jackson, 2000). Best-fit models were chosen based on simplicity, R-squared value, and PRESS values: a significant MLR model with the lowest PRESS value and the highest R-squared value was considered the "best"-that is, the most parsimonious model.

\section{Sampling Results}

This section presents a summary of the fish- and invertebrate-assemblage samples and describes the characteristics of water-quality samples collected throughout the New Jersey Pinelands study reaches.

\section{Fish}

Fourteen native and several non-native fish species were collected in New Jersey Pinelands streams during this study (also see Zampella and Bunnell, 1998). Hastings (1984) categorized the native Pinelands fish as being either restrictedcharacteristic or widespread-characteristic species (table 2). In New Jersey, those species identified as being restricted-characteristic are mostly limited to the interior Pinelands, whereas the widespread-characteristic species are distributed peripherally in the Pinelands and in many other streams throughout New Jersey. Native Pinelands fish species are adapted to the shallow and slow-moving waters that typify Pinelands streams; however, the conditions associated with some small headwaters streams (low pH and DO) may also limit the distribution of some species and influence species richness. Table 2 shows the biogeographical classification of the fish species collected at all sampling reaches during this study.

Fish were collected during high- and low-flow periods to assess interannual variability in species distribution. Twentyone different species were collected, for a total of 6,100 fish

Table 2. Taxonomic list and biogeographical classification of fish species collected in 43 New Jersey Pinelands stream reaches.

[NW, native widespread; I, introduced; P, peripheral; NR, native restricted]

\begin{tabular}{|c|c|c|c|}
\hline Common name $^{1}$ & Latin name $^{1}$ & Abbreviation & Distribution $^{2}$ \\
\hline Tessellated darter & Etheostoma olmstedi & TD & $\mathrm{P}$ \\
\hline Largemouth bass & Micropterus salmoides & LMB & I \\
\hline Creek chubsucker & Erimyzon oblongus & $\mathrm{CCS}$ & NW \\
\hline Pumpkinseed & Lepomis gibbosus & PS & $\mathrm{P}$ \\
\hline Banded sunfish & Enneacanthus obesus & BDS & NR \\
\hline Blackbanded sunfish & Enneacanthus chaetodon & BBDS & NR \\
\hline Bluespotted sunfish & Enneacanthus gloriosus & BSS & NW \\
\hline Mud sunfish & Acantharchus pomotis & MSF & NR \\
\hline Bluegill & Lepomis macrochirus & BG & I \\
\hline American eel & Anquilla rostrata & EEL & NW \\
\hline Pirate perch & Aphredoderus sayanus & PP & NR \\
\hline Yellow bullhead & Ameiurus natalis & YBH & NR \\
\hline Brown bullhead & Ameiurus nebulosus & $\mathrm{BBH}$ & $\mathrm{P}$ \\
\hline Swamp darter & Etheostoma fusiforme & SWD & NR \\
\hline Eastern mudminnow & Umbra pygmaea & MM & NW \\
\hline Redfin pickerel & Esox americanus americanus & RFP & NW \\
\hline Chain pickerel & Esox niger & $\mathrm{CP}$ & NW \\
\hline Tadpole madtom & Noturus gyrinus & TPM & NW \\
\hline Golden shiner & Notemigonus crysoleucas & GSH & $\mathrm{P}$ \\
\hline Channel catfish & Ictalurus punctatus & $\mathrm{CCF}$ & I \\
\hline Black crappie & Promoxis nigromaculatus & BCR & I \\
\hline
\end{tabular}

${ }^{1}$ Nomenclature corresponds with that presented in Nelson and others (2004).

${ }^{2}$ Fish-species distributions are based on classifications by Hastings (1984). 
(table 3 ). The most common species captured throughout the 43 stream reaches was the eastern mudminnow (MM), which accounted for 31 percent of the total fish abundance; banded sunfish (BDS) and American eel (EEL) represented 16 and 14 percent of the total abundance, respectively (table 3). Eight species (MM, chain pickerel (CP), swamp darter (SWD), tessellated darter (TD), BDS, EEL, pirate perch (PP), and yellow bullhead $(\mathrm{YBH})$ ) together accounted for more than 90 percent of the total abundance. Three species (black crappie, channel catfish, and golden shiner) were captured only once. MM and EEL were the most frequently encountered species (79.1 percent) (table 3$)$. CP (76.7 percent), SWD (59.3 percent), and BDS (58.1 percent) were also frequently captured throughout the study. Little difference in species abundance was observed between the high- and low-flow sampling periods and a regression relation of the axis I scores between these two sampling periods was near unity (fig. 2). This comparison was confirmed by analysis of similarities (ANOSIM: PRIMER-E v6), which showed no faunal difference between the high- and low-flow sampling periods (Global $\mathrm{R}=0.005 ; P=0.53$ ). As a result, these two datasets were pooled and all univariate and multivariate analyses were based on the combined high- and low-flow samples $(n=43)$.
Table 3. Relative abundance and frequency of occurrence of fish species collected at 43 New Jersey Pinelands stream reaches.

\begin{tabular}{|c|c|c|c|c|}
\hline Common name & Species & $\begin{array}{c}\text { Total } \\
\text { abundance }\end{array}$ & $\begin{array}{c}\text { Relative } \\
\text { abundance } \\
\text { (percent) }\end{array}$ & $\begin{array}{c}\text { Frequency of } \\
\text { occurrence } \\
\text { (percent) }\end{array}$ \\
\hline Eastern mudminnow & MM & 1,884 & 31.0 & 79.1 \\
\hline Banded sunfish & BDS & 997 & 16.0 & 58.1 \\
\hline American eel & EEL & 849 & 14.0 & 79.1 \\
\hline Tessellated darter & TD & 520 & 8.5 & 46.5 \\
\hline Swamp darter & SWD & 491 & 8.0 & 59.3 \\
\hline Chain pickerel & $\mathrm{CP}$ & 288 & 4.7 & 76.7 \\
\hline Pirate perch & PP & 270 & 4.4 & 55.8 \\
\hline Yellow bullhead & YBH & 253 & 4.1 & 54.7 \\
\hline Creek chubsucker & $\mathrm{CCS}$ & 128 & 2.1 & 41.9 \\
\hline Redfin pickerel & RFP & 94 & 1.5 & 46.5 \\
\hline Tadpole madtom & TPM & 80 & 1.3 & 29.1 \\
\hline Pumpkinseed & PS & 70 & 1.1 & 23.3 \\
\hline Mud sunfish & MSF & 48 & 0.8 & 34.9 \\
\hline Bluespotted sunfish & BSS & 36 & 0.6 & 20.9 \\
\hline Bluegill & BG & 32 & 0.5 & 14.0 \\
\hline Blackbanded sunfish & BBDS & 23 & 0.4 & 11.6 \\
\hline Brown bullhead & $\mathrm{BBH}$ & 20 & 0.3 & 14.0 \\
\hline Largemouth bass & LMB & 14 & 0.2 & 12.8 \\
\hline Channel catfish & $\mathrm{CCF}$ & 1 & 0.0 & 1.2 \\
\hline Golden shiner & GS & 1 & 0.0 & 1.2 \\
\hline Black crappie & BCR & 1 & 0.0 & 1.2 \\
\hline
\end{tabular}

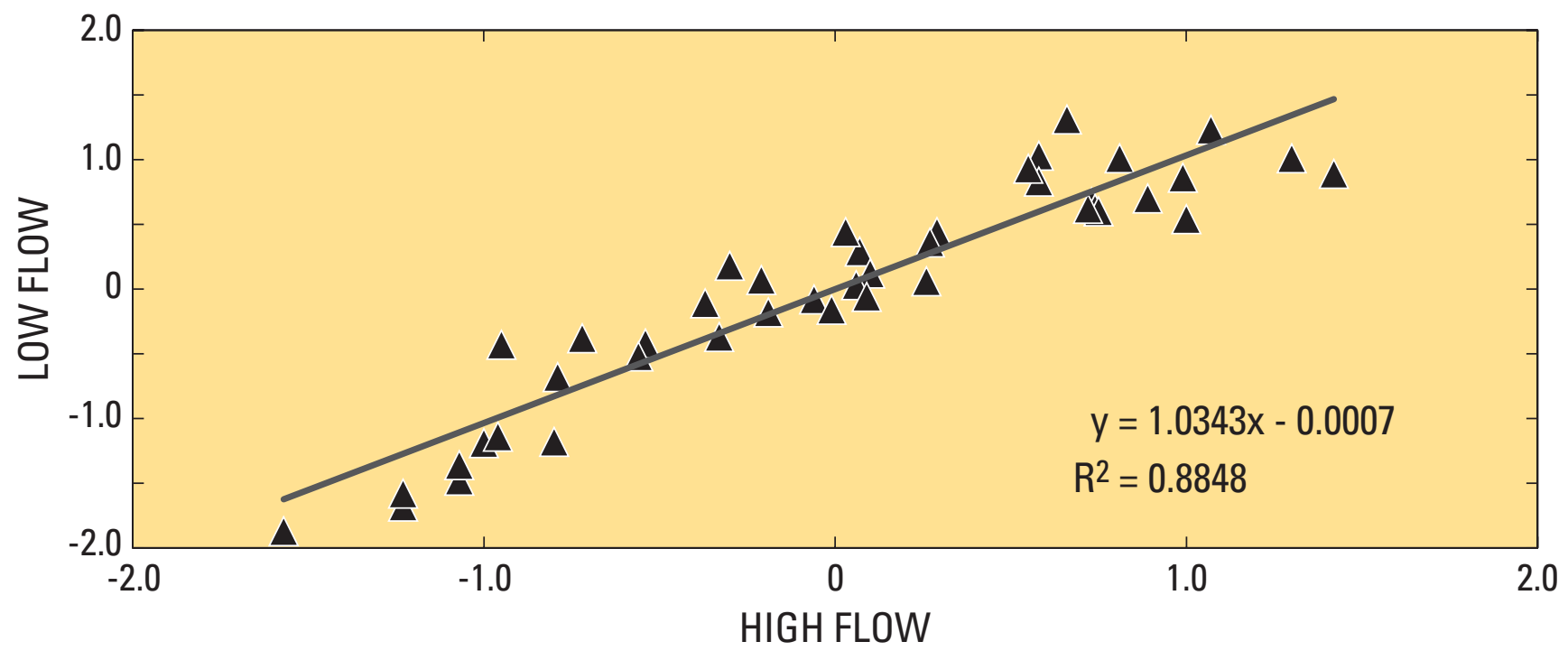

Figure 2. Regression relation for fish ordination axis I scores between high- and low-flow sampling periods at 43 New Jersey Pinelands stream reaches. 


\section{Aquatic Invertebrates}

Compilation and processing of the aquatic-invertebrate assemblage data through IDAS for the 43 study sites produced an analysis dataset with 125 taxa (table 4). Number of taxa at a site ranged from 9 to 49 (median 37), and total abundance ranged from 84 to 432 (median 323). Tribelos $s p$. was the most abundant benthic invertebrate taxon identified during this study, accounting for 8.1 percent of the aquaticinvertebrate assemblage and occurring at 72 percent of the sampling sites (table 4). Thienemannimyia sp. and Simulim sp. accounted for 6.9 and 6.6 percent of the total abundance, respectively. Other taxa that were present in significant quantities included Caecidotea sp. (6.4 percent), Leuctra sp. (5.73 percent), Hydropsyche sp. (4.0 percent), Stenelmis sp. (3.9 percent), Polypedilum sp. (3.7 percent), and Ancyronyx $s p$. (3.1 percent). The most frequently occurring aquatic invertebrates included Thienemannimyia sp. (88 percent), Polypedilum sp. (85 percent), Bezzia/Palpomyia sp. (79 percent), Hydropsyche sp. (78 percent), and Enchytraeidae (76 percent) (table 4 ).

Analysis of similarities (ANOSIM: PRIMER-E v6) confirmed that no distinct faunal differences were present between the high- and low-flow sampling periods (Global $\mathrm{R}=0.116 ; P=0.10)$. Therefore, these two datasets, like the fish data, were pooled and all further univariate and multivariate analyses were based on the pooled samples.

\section{Water Quality}

Variation in Pinelands streamwater quality is typically associated with the extent of land-use alteration in a watershed (Zampella and others, 2007). Pinelands streams with some upstream basin development tend to display slightly higher $\mathrm{pH}$ and $\mathrm{SC}$ values than those with little altered land. In general, average daily water temperatures increase with the percentage of urbanization in the basin, and these warmer temperatures help to explain decreases in concentrations of DO. Median values were calculated for all of the water-quality properties at each of the sampled streams (table 5). Values of $\mathrm{pH}$ for all study streams ranged from 4.1 to 6.4 and SC ranged from 33 to $304 \mu \mathrm{S} / \mathrm{cm}$ (table 5). Median water temperature and DO concentration ranged from 12.3 to $19.3^{\circ} \mathrm{C}$ and 4.3 to $9.7 \mathrm{mg} / \mathrm{L}$, respectively. SC was highest at PumpCed and lowest at SktHam, pH was lowest at PenSwmp, and DO was lowest at BatTab.

Table 4. Relative abundance and frequency of occurrence of aquatic-invertebrate taxa for samples collected at 43 New Jersey Pinelands stream reaches.

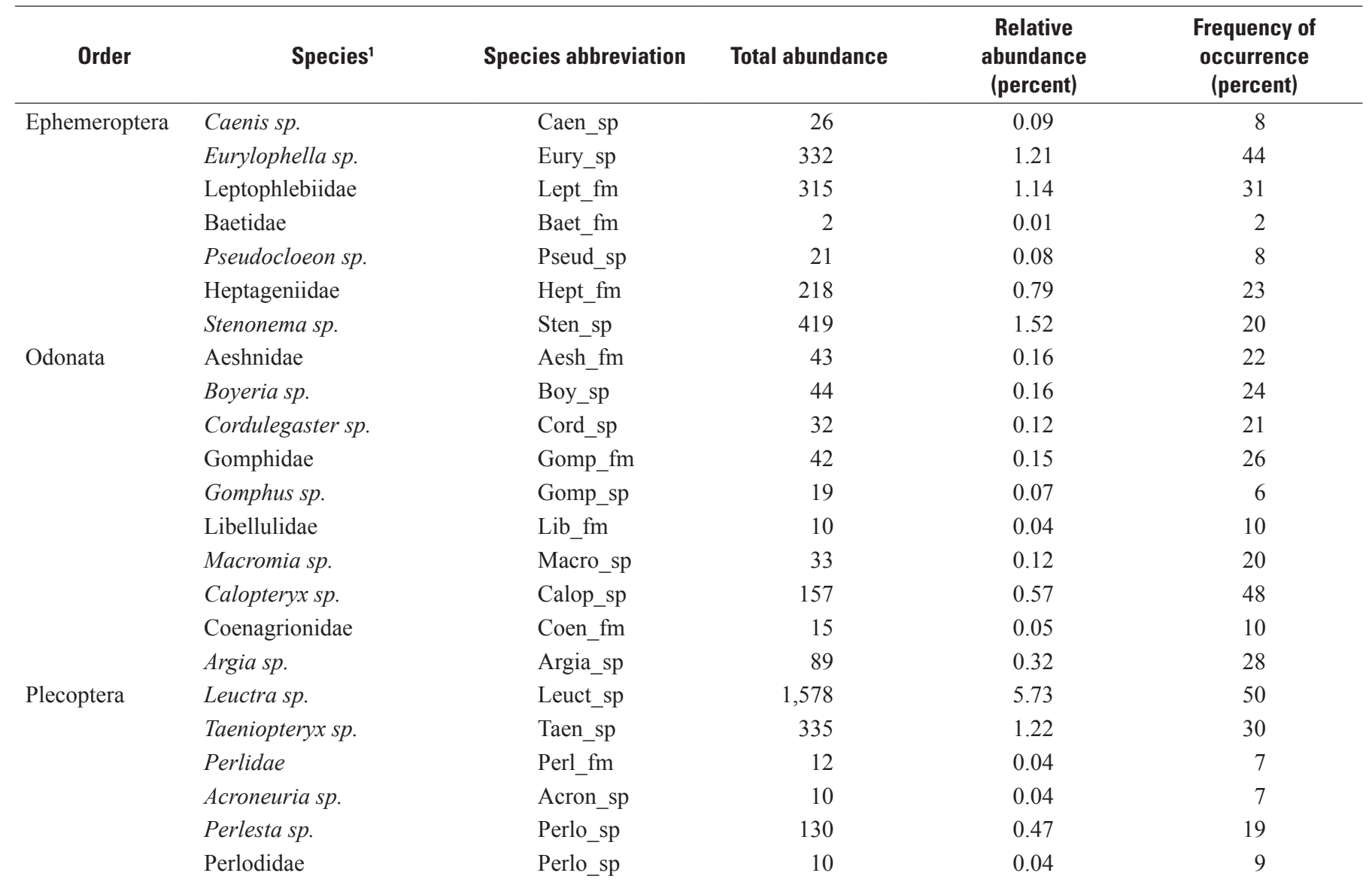


Table 4. Relative abundance and frequency of occurrence of aquatic-invertebrate taxa for samples collected at 43 New Jersey Pinelands stream reaches. - Continued

\begin{tabular}{|c|c|c|c|c|c|}
\hline Order & Species $^{1}$ & Species abbreviation & Total abundance & $\begin{array}{c}\text { Relative } \\
\text { abundance } \\
\text { (percent) }\end{array}$ & $\begin{array}{c}\text { Frequency of } \\
\text { occurrence } \\
\text { (percent) }\end{array}$ \\
\hline Hemiptera & Corixidae & Corix_fm & 10 & 0.04 & 7 \\
\hline \multirow[t]{8}{*}{ Coleoptera } & Hydroporinae & Hydr_fm & 46 & 0.17 & 23 \\
\hline & Neoporus sp. & Neop_sp & 40 & 0.15 & 20 \\
\hline & Dineutus sp. & Dine_sp & 242 & 0.88 & 66 \\
\hline & Peltodytes sp. & Pelto_sp & 7 & 0.03 & 6 \\
\hline & Ancyronyx sp. & Ancy_sp & 842 & 3.06 & 67 \\
\hline & Macronychus sp. & Macrn_sp & 506 & 1.84 & 33 \\
\hline & Microcylloepus sp. & Micro_sp & 121 & 0.44 & 15 \\
\hline & Stenelmis sp. & Stene_sp & 1,074 & 3.90 & 70 \\
\hline Megaloptera & Sialis $s p$ & Sial_sp & 203 & 0.74 & 67 \\
\hline \multirow[t]{26}{*}{ Diptera } & Chironomus sp. & Chiro_sp & 89 & 0.32 & 13 \\
\hline & Cryptochironomus sp. & Crypt_sp & 204 & 0.74 & 55 \\
\hline & Demicryptochironomus sp. & Demi_sp & 21 & 0.08 & 15 \\
\hline & Nilothauma $s p$ & Nilo_sp & 44 & 0.16 & 19 \\
\hline & Paracladopelma sp. & Parac_sp & 15 & 0.05 & 8 \\
\hline & Paratendipes sp. & Parat_sp & 22 & 0.08 & 12 \\
\hline & Phaenopsectra sp. & Phaen_sp & 84 & 0.31 & 21 \\
\hline & Polypedilum sp. & Polyp_sp & 1,005 & 3.65 & 85 \\
\hline & Stelechomyia sp. & Stele_sp & 72 & 0.26 & 29 \\
\hline & Corynoneura sp. & Coryn_sp & 44 & 0.16 & 22 \\
\hline & Cricotopus sp. & Crico_sp & 58 & 0.21 & 13 \\
\hline & Heterotrissocladius sp. & Heter_cp & 45 & 0.16 & 22 \\
\hline & Limnophyes sp. & Limno_sp & 28 & 0.10 & 16 \\
\hline & Nanocladius sp. & Nano_sp & 13 & 0.05 & 8 \\
\hline & Orthocladius sp. & Ortho_sp & 86 & 0.31 & 36 \\
\hline & Parachaetocladius sp. & Parch_sp & 88 & 0.32 & 34 \\
\hline & Parakiefferiella sp. & Parki_sp & 90 & 0.33 & 22 \\
\hline & Parametriocnemus sp. & Parm_sp & 60 & 0.22 & 19 \\
\hline & Psectrocladius sp. & Psec_sp & 73 & 0.27 & 19 \\
\hline & Rheocricotopus sp. & Rheoc_sp & 95 & 0.35 & 38 \\
\hline & Stilocladius sp. & Stilo_sp & 25 & 0.09 & 12 \\
\hline & Thienemanniella sp. & Thien_sp & 48 & 0.17 & 21 \\
\hline & Tvetenia $s p$ & Tvet_sp & 303 & 1.10 & 30 \\
\hline & Unniella sp. & Unni_sp & 67 & 0.24 & 14 \\
\hline & Xylotopus sp. & Xylo_sp & 163 & 0.59 & 31 \\
\hline & Clinotanypus sp. & Clino_sp & 93 & 0.34 & 30 \\
\hline
\end{tabular}


Table 4. Relative abundance and frequency of occurrence of aquatic-invertebrate taxa for samples collected at 43 New Jersey Pinelands stream reaches.-Continued

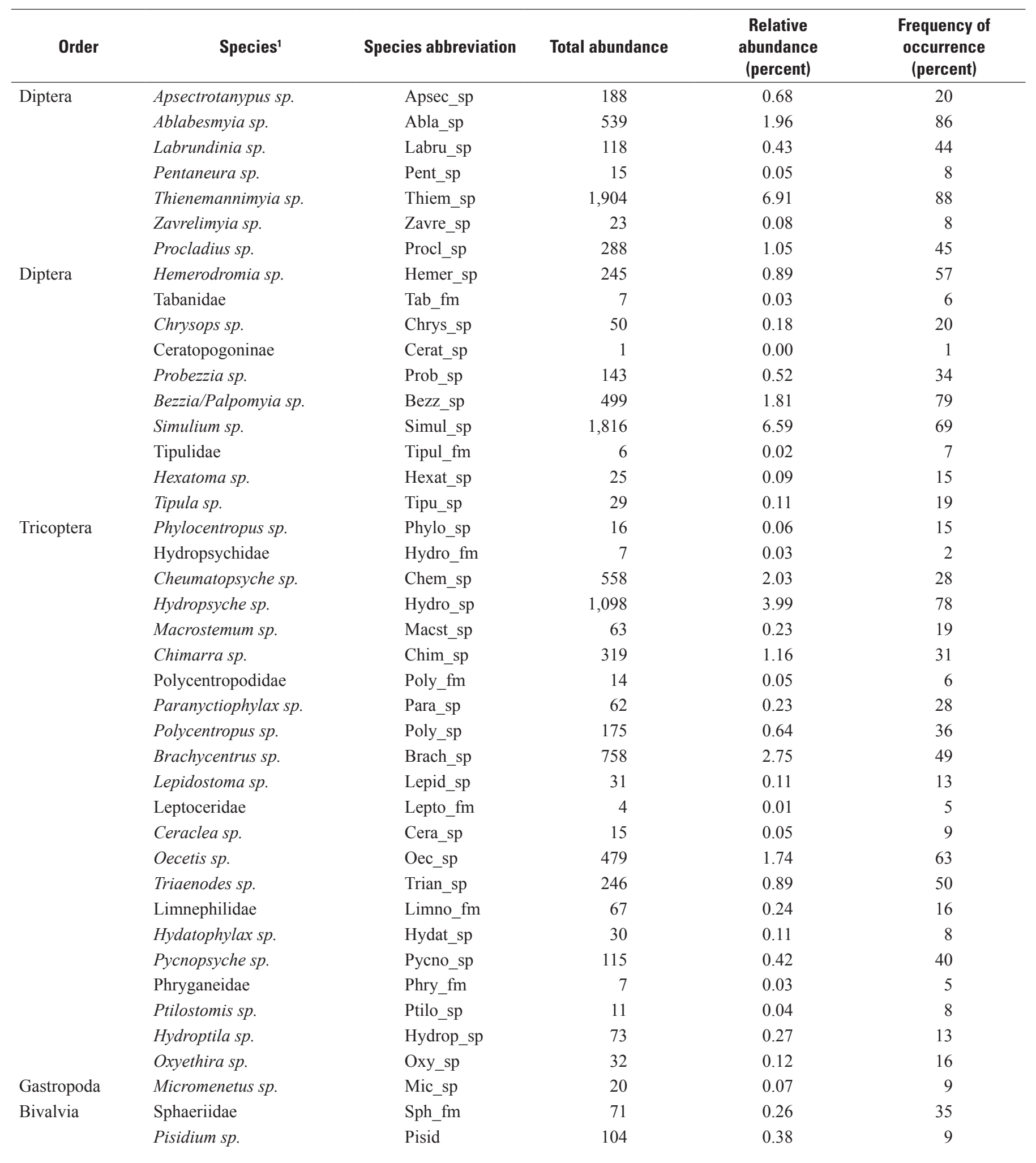


Table 4. Relative abundance and frequency of occurrence of aquatic-invertebrate taxa for samples collected at 43 New Jersey Pinelands stream reaches.-Continued

\begin{tabular}{|c|c|c|c|c|c|}
\hline Order & Species' & Species abbreviation & Total abundance & $\begin{array}{c}\text { Relative } \\
\text { abundance } \\
\text { (percent) }\end{array}$ & $\begin{array}{c}\text { Frequency of } \\
\text { occurrence } \\
\text { (percent) }\end{array}$ \\
\hline \multirow[t]{6}{*}{ Annelida } & Lumbriculidae & Lumb & 307 & 1.11 & 44 \\
\hline & Nais sp. & Nais_sp & 7 & 0.03 & 7 \\
\hline & Tubificidae & Tubif & 429 & 1.56 & 49 \\
\hline & Enchytraeidae & Ench_fm & 442 & 1.60 & 76 \\
\hline & Placobdella sp. & Plac_sp & 12 & 0.04 & 7 \\
\hline & Erpobdellidae & Erpo_sp & 16 & 0.06 & 14 \\
\hline \multirow[t]{2}{*}{ Acari } & Hygrobates sp. & Hygro_sp & 14 & 0.05 & 9 \\
\hline & Mideopsis sp. & Mid_sp & 32 & 0.12 & 21 \\
\hline \multirow[t]{3}{*}{ Crustacea } & Caecidotea sp. & Caec_sp & 1,761 & 6.40 & 65 \\
\hline & Synurella sp. & Syn_sp & 248 & 0.90 & 38 \\
\hline & Hyalella sp. & Hya_sp & 15 & 0.05 & 9 \\
\hline \multirow[t]{3}{*}{ Other taxa } & Turbellaria & Turb & 57 & 0.21 & 17 \\
\hline & Prostoma sp. & Pros_sp & 35 & 0.13 & 19 \\
\hline & Nematoda & Nema & 265 & 0.96 & 71 \\
\hline
\end{tabular}

${ }^{1}$ All taxonomic identifications were verified using the Integrated Taxonomic Information System (ITIS) (http://www.itis.gov).

Table 5. Median water-quality properties measured bimonthly at 15 New Jersey Pinelands stream sites.

$\left[\mu \mathrm{S} / \mathrm{cm}\right.$, microsiemens per centimeter; $\mathrm{mg} / \mathrm{L}$, milligrams per liter; ${ }^{\circ} \mathrm{C}$, degrees Celsius $]$

\begin{tabular}{lcccc}
\hline $\begin{array}{c}\text { Site } \\
\text { abbreviation }\end{array}$ & $\mathbf{p H}$ & $\begin{array}{c}\text { Specific } \\
\text { conductance } \\
(\boldsymbol{\mu S} / \mathbf{c m})\end{array}$ & $\begin{array}{c}\text { Dissolved-oxygen } \\
\text { concentration } \\
(\mathbf{m g} / \mathbf{L})\end{array}$ & $\begin{array}{c}\text { Water } \\
\text { temperature } \\
\left({ }^{\circ} \mathbf{C}\right)\end{array}$ \\
\hline BatTab & 4.22 & 47 & 4.34 & 14.2 \\
BatHigh & 5.25 & 52 & 9.21 & 12.3 \\
SkitHam & 4.41 & 33 & 8.67 & 12.7 \\
BatHam & 4.89 & 40 & 9.08 & 13.8 \\
Musk & 5.96 & 188 & 6.44 & 13.1 \\
SprHam & 5.98 & 117 & 8.06 & 12.9 \\
SprAts & 5.85 & 102 & 8.66 & 12.8 \\
PenSwmp & 4.07 & 44 & 7.92 & 12.8 \\
PumpCed & 6.22 & 304 & 6.53 & 16.4 \\
PumpElm & 6.27 & 85 & 8.31 & 19.3 \\
AlbElm & 6.40 & 86 & 8.95 & 14.4 \\
AlbHam & 6.29 & 77 & 9.68 & 18.4 \\
WBBass & 4.44 & 36 & 9.66 & 15.3 \\
Morses & 5.21 & 84 & 8.83 & 17.0 \\
MtMis & 4.30 & 38 & 5.18 & 15.6 \\
\hline
\end{tabular}




\section{Effects of Potential Changes in Streamflow Regime on Fish and Aquatic-Invertebrate Assemblages}

Flow variables describing magnitude, frequency, duration, timing, and rate of change were generated using HIT. Highly correlated variables were filtered by principal component and correlation analysis (see Data Collection and Analysis section) to obtain a greatly reduced subset of variables that explain the majority of variation in the complete set (Olden and Poff, 2003) for fish and invertebrate assemblages. To reduce the influence of land use on model development, all hydrologic or assemblage attributes that were correlated $(|r h o| \geq 0.5000)$ with anthropogenic disturbance variables (that is, urban and agricultural land use, $\mathrm{pH}$, or $\mathrm{SC}$ ) were eliminated from further analysis. Data on distribution and composition of fish and invertebrate assemblages, including dominant taxa, structural and functional metrics and indices, species traits (fish only), and NMS ordination axis I scores, were assembled. A series of univariate (correlation) and multivariate (MLR) response models using these hydrologic, assemblage, and other ancillary variables (for example, water-quality and land-use data) were developed to evaluate whether underlying anthropogenic processes are influencing the hydrologic gradient and to assess the relation between variability in the flow regime and fish and aquatic-invertebrate assemblage response in Pinelands streams.

\section{Fish-Species Response}

This section presents a summary of ordination, correlation, and multiple-regression analyses relating fish NMS ordination axis I scores to land use, water chemistry, and stream-reach characteristics, and identifies a reduced set of low- and annual-flow hydrologic variables for developing fish-assemblage flow-ecology response models for New Jersey Pinelands stream reaches.

\section{Ordination Results}

Results of 25 NMS iterations using the PRIMER software (Clarke and Gorley, 2006) indicated that the threedimensional solution was the best solution, with a final stress of 15.0. Higher dimensions did little to improve the model. Together, the three axes accounted for 76 percent of the variance in the analytical dataset. The first NMS axis accounted for the majority of the fish-assemblage variation (41 percent). The second and third axes accounted for a significant, but generally smaller, proportion of the overall variance (10 and 25 percent, respectively) and were not considered for further analysis.

\section{Land Use, Water Chemistry, Hydrology, and other Ancillary Data}

Percent urban land $(r h o=+0.7912)$ was the variable most highly correlated with fish axis I scores (table 6) and accounted for the greatest amount of variability in the fish MLR model (table 7). Other ancillary variables highly correlated with fish axis I scores were $\mathrm{pH}(r h o=+0.7182)$, aspect $(r h o=-0.7115)$, percent agricultural land $(r h o=+0.7064)$, and floating vegetation in the stream reach $(r h o=-0.5269)$.

Variation in the NMS axis 1 scores for fish was best explained by the interaction among percent urban land use and dissolved-oxygen concentration $\left(\mathrm{R}^{2}=0.5742\right.$; table 7$)$. This two-variable MLR model significantly predicts that components of the fish assemblage are modified along the hydrologic gradient, especially by land use. For example, the amount of urbanization in the catchment accounted for the majority of the overall variability ( $>40$ percent). Multiple-regression procedures indicated that estimates of model-prediction error and precision were not highly biased, and variance inflation factors were low (table 7). Correlation coefficients were not inflated and comparison between actual model values and those predicted through an $\mathrm{n}-1$ validation approach (that is, the PRESS statistic) differed little.

Of the 163 hydrologic variables aggregated for this study, only a subset met the conservative screening criteria and was retained for use in developing fish-assemblage flow-ecology response models. These variables represent components of mean annual flow, mean and median minimum annual flows, variability across minimum monthly flows, and duration of minimum flows (table 8).

\section{Aquatic-Invertebrate Response}

This section presents a summary of ordination, correlation, and multiple-regression analyses relating invertebrate NMS ordination axis I scores to land use, water chemistry, and stream-reach characteristics, and identifies a reduced set of low- and annual-flow hydrologic variables for developing invertebrate-assemblage flow-ecology response models for New Jersey Pinelands stream reaches.

\section{Ordination Results}

Results of 25 NMS iterations indicated that the threedimensional solution was the best solution, with a final stress of 14.0. Higher dimensions did little to improve the model. Together, the three axes accounted for 86 percent of the variance in the analytical dataset. The first NMS axis accounted for the majority of invertebrate-assemblage variation (50 percent). The second and third axes accounted for a significant but generally smaller proportion of the overall variance (11 and 25 percent, respectively) and were not considered for further analysis. 
Table 6. Land-use, water-chemistry, and stream-reach characteristics that are significantly correlated with fish axis I scores for New Jersey Pinelands stream reaches.

[N, number of observations; rho, Spearman's $r h o ; \mathrm{mg} / \mathrm{L}$, milligrams per liter; $\mu \mathrm{S} / \mathrm{cm}$, microsiemens per centimeter; $\mathrm{H}+$, hydrogen ion; <, less than]

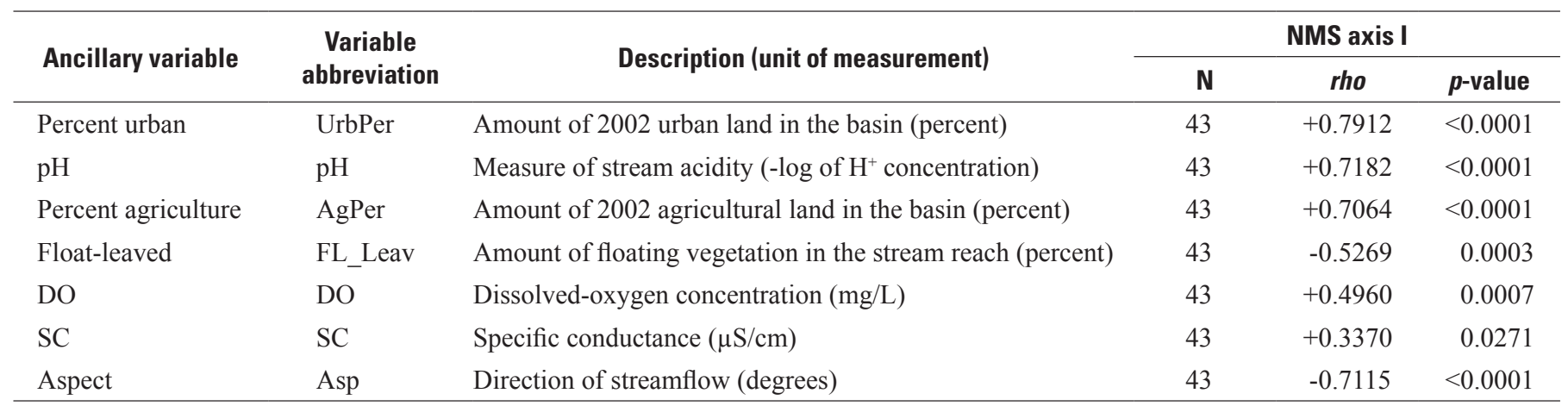

Table 7. Multiple-regression model relating fish NMS axis I scores to basin characteristics for New Jersey Pinelands stream reaches.

$\left[\mathrm{R}^{2}, \mathrm{R}\right.$-squared; <, less than; VIF, Variable Inflation Factor; variable definitions are found in table 9]

\begin{tabular}{ccccccc}
\hline Number in model & Model R $^{2}$ & Model $\boldsymbol{p}$-value & Partial $\mathbf{R}^{\mathbf{2}}$ & $\boldsymbol{p}$-value & Variable abbreviation & VIF \\
\hline \multirow{2}{*}{2} & \multirow{2}{*}{0.5742} & $<0.0001$ & +0.4388 & $<0.0001$ & UrbPer & 1.07 \\
& & & +0.1354 & 0.0010 & DO & 1.07 \\
\hline
\end{tabular}

Table 8. Reduced set of low- and annual-flow hydrologic variables that met the screening criteria and represent the hydrologic basis for developing fish-assemblage flow-ecology response models for New Jersey Pinelands stream reaches.

$\left[\mathrm{m}^{3} / \mathrm{s}\right.$, cubic meters per second; D, dimensionless; $\mathrm{N}$, number of observations; variables were screened for use in model development using known indicators of anthropogenic degradation (that is, urban and agricultural land use, $\mathrm{pH}$, and specific conductance). Refer to Kennen and others (2007) for a complete description of hydrologic-variable calculation. Hydrologic-variable calculations are based on the study period of record from May 2004 to May 2006]

\begin{tabular}{|c|c|c|c|c|c|}
\hline $\begin{array}{l}\text { Hydrologic } \\
\text { index }\end{array}$ & Description (unit of measurement) & $\mathbf{N}$ & Mean & Minimum & Maximum \\
\hline MA1 & Mean of the daily mean flow values for the entire flow record $\left(\mathrm{m}^{3} / \mathrm{s}\right)$ & 43 & 0.51 & 0.01 & 1.09 \\
\hline MA16 & Mean of all May flow values over the entire record $\left(\mathrm{m}^{3} / \mathrm{s}\right)$ & 43 & 0.40 & 0.01 & 0.96 \\
\hline MA17 & Mean of all June flow values over the entire record $\left(\mathrm{m}^{3} / \mathrm{s}\right)$ & 43 & 0.29 & 0.01 & 0.73 \\
\hline MA19 & Mean of all August flow values over the entire record $\left(\mathrm{m}^{3} / \mathrm{s}\right)$ & 43 & 0.26 & 0.01 & 0.70 \\
\hline ML5 & Mean of the minimums of all May flow values over the entire record $\left(\mathrm{m}^{3} / \mathrm{s}\right)$ & 43 & 0.25 & 0.01 & 0.65 \\
\hline ML9 & Mean of the minimums of all September flow values over the entire record $\left(\mathrm{m}^{3} / \mathrm{s}\right)$ & 43 & 0.19 & 0.00 & 0.51 \\
\hline ML13 & Variability (coefficient of variation) across minimum monthly flow values (percent) & 43 & 199.40 & 55.35 & 206.43 \\
\hline ML16 & Median of annual minimum flows (D) & 43 & 0.18 & 0.02 & 0.37 \\
\hline
\end{tabular}




\section{Land Use, Water Chemistry, Hydrology, and other Ancillary Data}

Percent urban land ( $r h o=+0.8486$ ) was the variable most highly correlated with invertebrate axis I scores (table 9). Other ancillary variables highly correlated with invertebrate axis I scores were $\mathrm{pH}(r h o=+0.8207)$, aspect $(r h o=-0.6665)$, percent agricultural land $(r h o=+0.7452)$, and floating vegetation in the stream reach $(r h o=-0.5635)$.

The NMS axis I score was best explained by the interaction among landscape configuration and water-quality characteristics (83 percent; table 10). Attempts to generate higher order models resulted in some undesirable collinearity among explanatory variables, as indicated by elevated VIFs (that is, $>10.0$ ). Results of $n-1$ validation procedures showed that estimates of model-prediction error and precision were not highly biased, variance inflation factors were relatively low (table 10), and correlation coefficients of the actual model were not inflated.

Only a subset of 163 hydrologic variables aggregated for this study met the screening criteria and was retained for use in developing invertebrate-assemblage flow-ecology response models. These variables represent components of mean annual flow, mean minimum annual flows, and duration of minimum flows (table 11).

\section{Flow-Ecology Response Relations}

Results of this study indicate that many mean monthly flow variables (that is, MA12-23) are highly intercorrelated and account for nearly the same proportion of the hydrologic variability (table 12). The variance of these flow-magnitude attributes can be summarized, for the most part, by using the mean of the daily mean flow values for the entire flow record (MA1; table 12) as a surrogate. The regression relation was strongest between MA1 and MA21 $\left(\mathrm{R}^{2}=0.9909\right)$. MA1, however, was calculated using the Hydrologic Indices Program (HIP) based on simulated hydrographs that were derived using the approach outlined in the Hydrologic Assessment section. For purposes of data accuracy and flow-metric validation, MA1 and the observed mean annual flow (acquired directly from the rated staff gages) were directly compared. Results of the regression relation indicate that the observed and calculated mean annual daily flow values are near unity (fig. 3). This result is consistent with metric-validation results previously published for all HIP metrics (see Henriksen and others, 2006; Kennen and others, 2007). Linear-regression results also indicate a high level of correspondence between measures of mean annual daily flow and basin size (table 12), further supporting the applicability of the hydrologic gradient approach used in this study.

Table 9. Land-use, water-chemistry and stream-reach characteristics that are significantly correlated with aquatic-invertebrate axis I scores for New Jersey Pinelands stream reaches.

[N, number of observations; rho, Spearman's rho; mg/L, milligrams per liter; $\mu \mathrm{S} / \mathrm{cm}$, microsiemens per centimeter; $\mathrm{H}^{+}$, Hydrogen ion; <, less than]

\begin{tabular}{|c|c|c|c|c|c|}
\hline \multirow{2}{*}{ Ancillary variables } & \multirow{2}{*}{$\begin{array}{c}\text { Variable } \\
\text { abbreviation }\end{array}$} & \multirow{2}{*}{ Description (unit of measurement) } & \multicolumn{3}{|c|}{ NMS Axis I } \\
\hline & & & $\mathbf{N}$ & rho & p-value \\
\hline Percent urban & UrbPer & Amount of 2002 urban land in the basin (percent) & 43 & +0.8486 & $<0.0001$ \\
\hline Percent agriculture & AgPer & Amount of 2002 agricultural land in the basin (percent) & 43 & +0.7452 & $<0.0001$ \\
\hline Float-leaved & FL_Leav & Amount of floating vegetation in the stream reach (percent) & 43 & -0.5635 & $<0.0001$ \\
\hline DO & DO & Dissolved-oxygen concentration (mg/L) & 43 & +0.3721 & 0.0140 \\
\hline Aspect & Aspect & Direction of streamflow (degrees) & 43 & -0.6665 & $<0.0001$ \\
\hline
\end{tabular}

Table 10. Multiple-regression model relating invertebrate NMS axis I scores to basin characteristics for New Jersey Pinelands stream reaches.

[ $\mathrm{R}^{2}$, R-squared; VIF, Variable Inflation Factor; variable definitions can be found in table 9]

\begin{tabular}{|c|c|c|c|c|c|c|}
\hline Number in model & $\begin{array}{c}\text { Model } \\
\mathbf{R}^{2} \\
\end{array}$ & $\begin{array}{c}\text { Model } \\
p \text {-value }\end{array}$ & Partial $\mathbf{R}^{2}$ & $p$-value & $\begin{array}{c}\text { Variable } \\
\text { abbreviation }\end{array}$ & VIF \\
\hline \multirow{2}{*}{3} & \multirow{2}{*}{0.8295} & \multirow{2}{*}{$<0.0001$} & +0.6990 & 0.0013 & UrbPer & 3.50 \\
\hline & & & +0.0122 & 0.0003 & $\mathrm{SC}$ & 1.35 \\
\hline
\end{tabular}


Table 11. Reduced set of low- and annual-flow hydrologic variables that met the screening criteria and represent the hydrologic basis for developing invertebrate-assemblage flow-ecology response models.

$\left[\mathrm{m}^{3} / \mathrm{s}\right.$, cubic meters per second; $\mathrm{N}$, number of observations; variables were screened for use in model development using known indicators of anthropogenic degradation (that is, urban and agricultural land use, $\mathrm{pH}$, and specific conductance). Refer to Kennen and others (2007) for a complete description of hydrologicvariable calculation. Hydrologic-variable calculations are based on the study period of record from May 2004 to May 2006]

\begin{tabular}{llllll}
\hline $\begin{array}{c}\text { Hydrologic } \\
\text { index }\end{array}$ & \multicolumn{1}{c}{ Description (unit of measurement) } & N & Mean & Minimum & Maximum \\
\hline MA1 & Mean of the daily mean flow values for the entire flow record $\left(\mathrm{m}^{3} / \mathrm{s}\right)$ & 43 & 0.51 & 0.01 & 1.09 \\
MA12 & Mean of all January flow values over the entire record $\left(\mathrm{m}^{3} / \mathrm{s}\right)$ & 43 & 0.60 & 0.08 & 1.47 \\
MA13 & Mean of all February flow values over the entire record $\left(\mathrm{m}^{3} / \mathrm{s}\right)$ & 43 & 0.45 & 0.01 & 0.97 \\
MA14 & Mean of all March flow values over the entire record $\left(\mathrm{m}^{3} / \mathrm{s}\right)$ & 43 & 0.39 & 0.01 & 0.83 \\
MA15 & Mean of all April flow values over the entire record $\left(\mathrm{m}^{3} / \mathrm{s}\right)$ & 43 & 0.53 & 0.01 & 1.26 \\
MA17 & Mean of all June flow values over the entire record $\left(\mathrm{m}^{3} / \mathrm{s}\right)$ & 43 & 0.29 & 0.01 & 0.73 \\
MA20 & Mean of all September flow values over the entire record $\left(\mathrm{m}^{3} / \mathrm{s}\right)$ & 43 & 0.44 & 0.01 & 0.99 \\
MA21 & Mean of all October flow values over the entire record $\left(\mathrm{m}^{3} / \mathrm{s}\right)$ & 43 & 0.35 & 0.01 & 0.72 \\
MA22 & Mean of all November flow values over the entire record $\left(\mathrm{m}^{3} / \mathrm{s}\right)$ & 43 & 0.33 & 0.01 & 0.75 \\
MA23 & Mean of all December flow values over the entire record $\left(\mathrm{m}^{3} / \mathrm{s}\right)$ & 43 & 0.50 & 0.01 & 1.14 \\
ML8 & Mean of the minimums of all August flow values over the entire record $\left(\mathrm{m}^{3} / \mathrm{s}\right)$ & 43 & 0.16 & 0.00 & 0.46 \\
ML9 & Mean of the minimums of all September flow values over the entire record $\left(\mathrm{m}^{3} / \mathrm{s}\right)$ & 43 & 0.19 & 0.00 & 0.51 \\
DL4 & Mean of annual minimum of 30-day moving average flow $\left(\mathrm{m}^{3} / \mathrm{s}\right)$ & 43 & 0.19 & 0.00 & 0.52 \\
DL5 & Mean of annual minimum of 90 -day moving average flow $\left(\mathrm{m}^{3} / \mathrm{s}\right)$ & 43 & 0.29 & 0.01 & 0.73 \\
\hline
\end{tabular}

Table 12. Regression relations (R-squared values) between mean monthly flow variables and the mean of all daily flows for the entire flow record (MA1) and drainage area for New Jersey Pinelands stream reaches.

[Variable definitions can be found in tables 8 and 11; significance for all regression relations was at the $p<0.0001$ level; --, not applicable]

\begin{tabular}{ccc}
\hline Hydrologic variable & MA1 & Drainage area \\
\hline MA1 & -- & 0.9536 \\
MA12 & 0.8940 & 0.8029 \\
MA13 & 0.9812 & 0.9213 \\
MA14 & 0.9870 & 0.9409 \\
MA15 & 0.8912 & 0.8060 \\
MA16 & 0.8627 & 0.8833 \\
MA17 & 0.6798 & 0.7367 \\
MA18 & 0.9194 & 0.9257 \\
MA19 & 0.7672 & 0.8021 \\
MA20 & 0.9572 & 0.8793 \\
MA21 & 0.9909 & 0.9596 \\
MA22 & 0.9700 & 0.9503 \\
MA23 & 0.9687 & 0.8926 \\
\hline
\end{tabular}




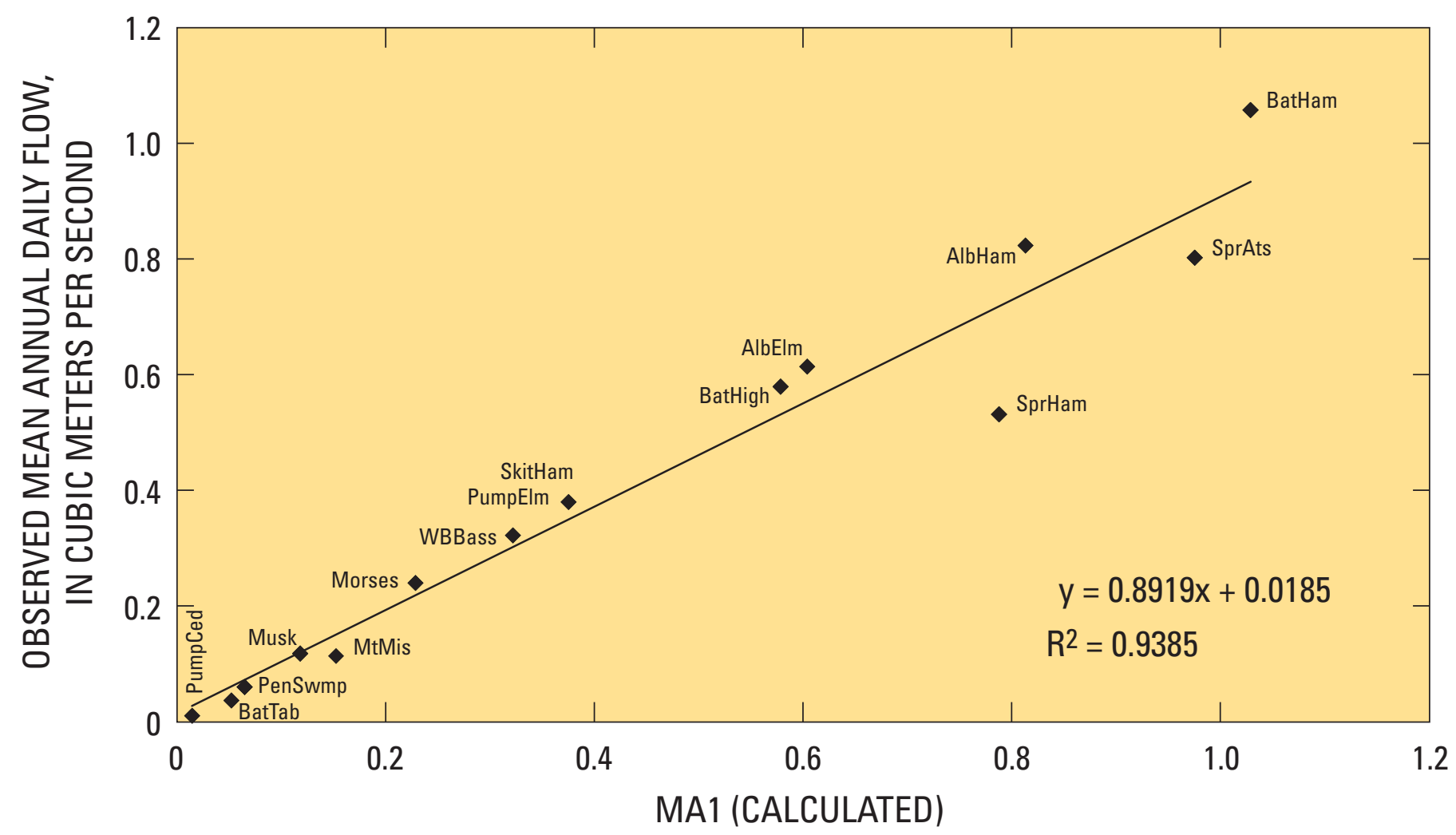

Figure 3. Regression relation between MA1 (calculated using Hydrologic Indices Tool) and the observed mean annual daily flow at 15 New Jersey Pinelands stream sites. (Refer to table 1 for detailed site information.)

Some environmental factors are also known to vary with streamflow (for example, DO), and many fish and invertebrate taxa in lotic systems depend on the availability of DO for survival (Hynes, 1970). DO concentrations in streams typically increase with decreasing water temperature, increasing turbulence, and increasing surface area (Allan, 1995). Few interior Pinelands streams, however, would be considered turbulent. Therefore, DO concentrations are likely more dependent on stream temperature and surface area (that is, stream size). In this study, DO concentrations generally appeared to increase with increasing MA1 values for Pinelands streams (fig. 4, $\mathrm{R}^{2}=0.6075$ ). This relation, although not surprising, may contribute to a more complete interpretation of the aquatic-assemblage response along the hydrologic gradient. For example, organisms that are considered to be intolerant of changes in flow conditions are also likely to be intolerant of other environmental stressors, such as low DO conditions (U.S. Environmental Protection Agency, 2006). This covariation may help to explain, in part, the strong flow-ecology response relations established between intolerant and tolerant invertebrate taxa and MA1 (figs. 5a and 5d, respectively), as well as the inverse relation established between MA1 and mudminnows (fig. 6c). Mudminnows are commonly associated with slowmoving backwater areas and are known to be highly tolerant of low levels of DO (Hastings, 1984; Jenkins and Burkhead, 1993). Evaluating the covariation among habitat attributes and flow processes may help to avoid overestimating the importance of flow-ecology response relations (Snelder and Lamouroux, 2010). The broader effects of variation associated with habitat attributes in this study were investigated using correlation and MLR for fish and invertebrate assemblages. Only the percent of floating vegetation in the stream reach (FL_Leav) was found to be significantly correlated with the fish- and invertebrate-axis scores (tables 6 and 9, respectively), however; FL_Leav was not found to account for a significant portion of the variation in the MLR models (tables 7 and 10, respectively). Further analysis indicated that habitat attributes such as stream depth $(r h o=0.5030)$ and stream-bank height $(r h o=0.6318)$ were significantly correlated with MA1; however, this finding is not unexpected as stream size and streamflow are highly related (fig. 3).

The success of this project depended in part on basin size (that is, the hydrologic gradient) accounting for a high proportion of the hydrologic variability without being influenced 


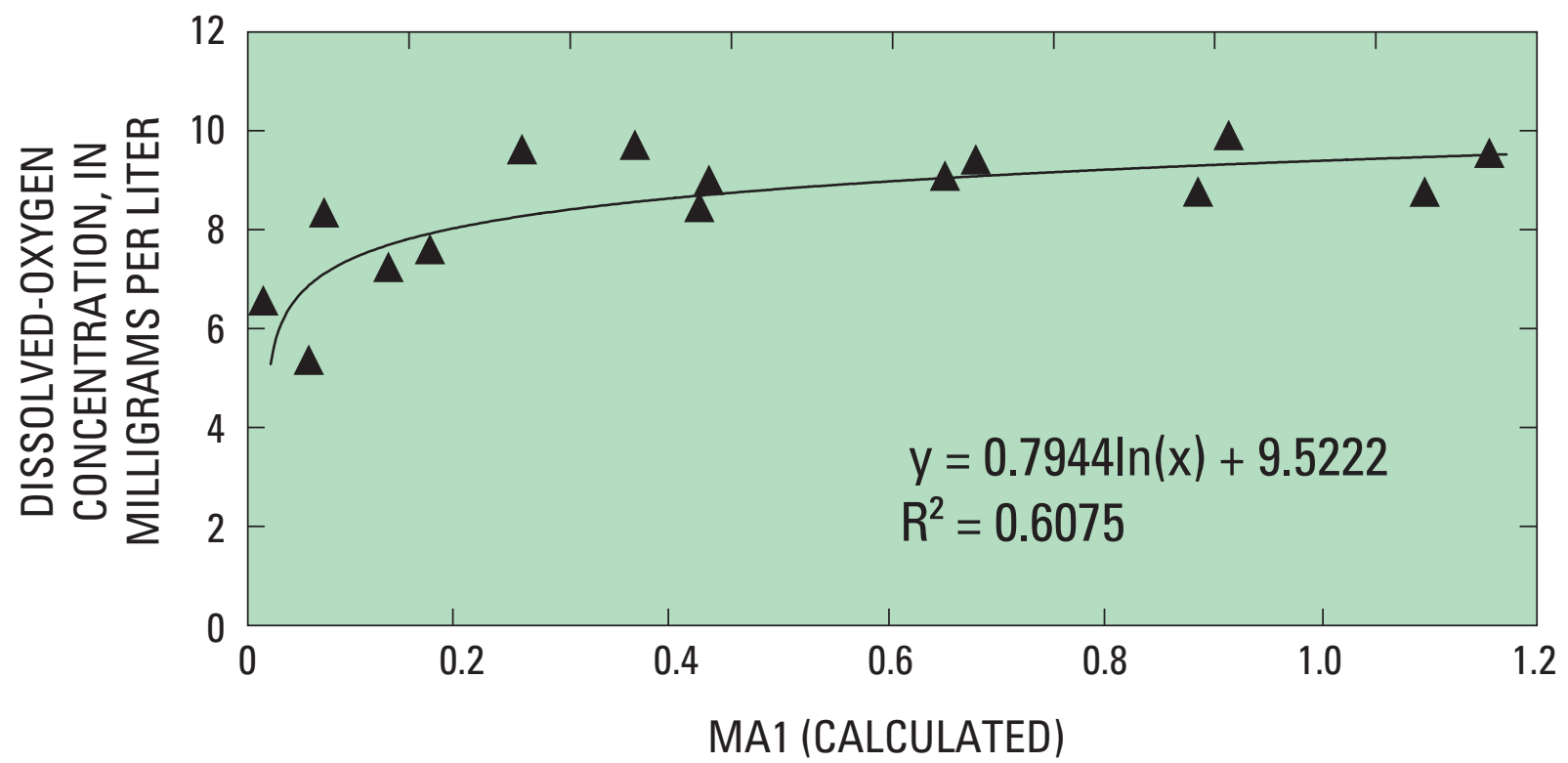

Figure 4. Regression relation between MA1 and mean dissolved-oxygen concentration at 15 New Jersey Pinelands stream sites.
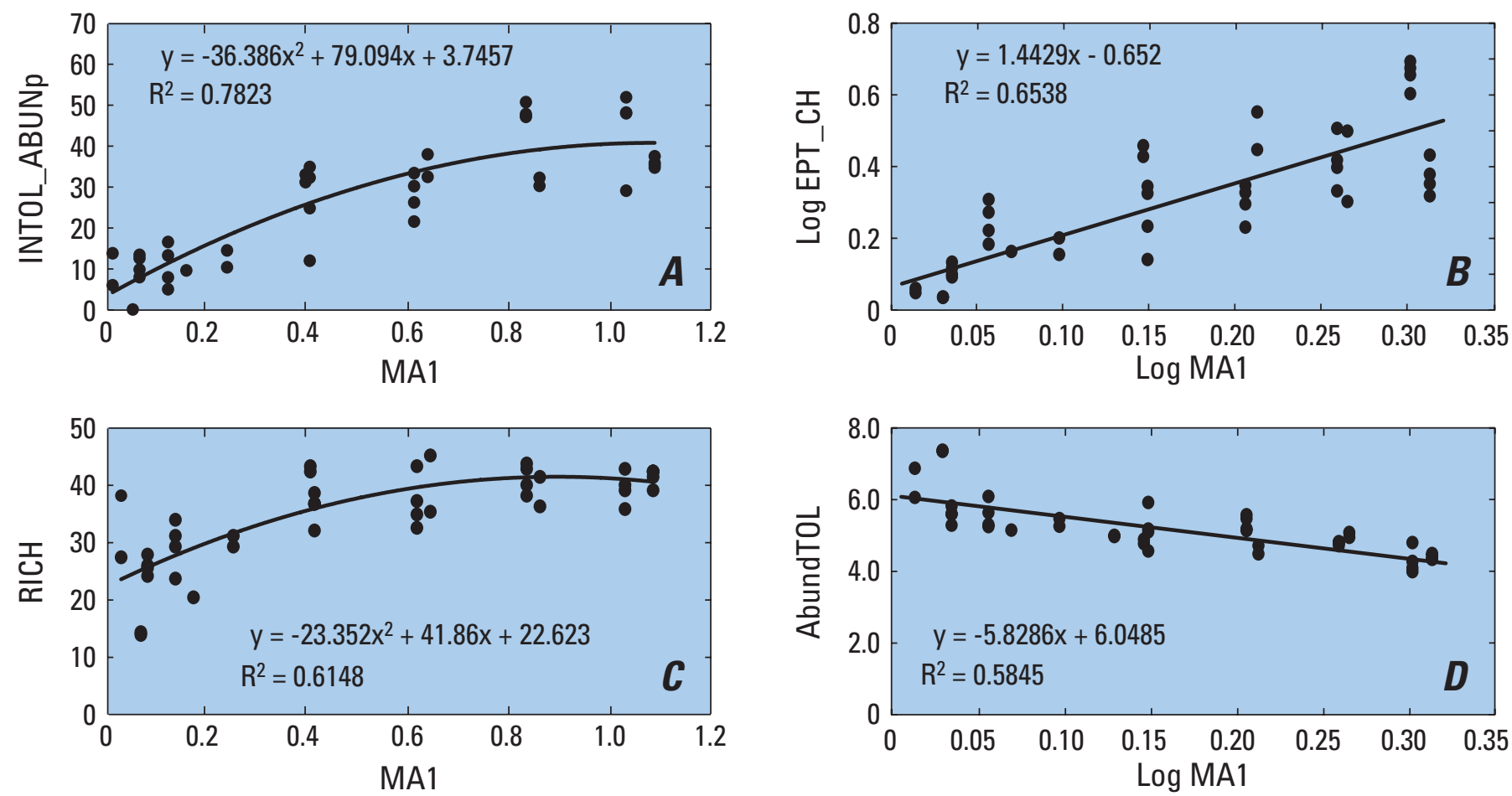

Figure 5. Invertebrate-assemblage flow-ecology response relations between the mean of the daily mean flow values for the entire flow record (MA1, in cubic meters per second) and $(A)$ INTOL_ABUNp, $(B)$ EPT_CH, $(C)$ RICH, and $(D)$ ABUNTOL. (Graphs A and C are fitted with a polynomial response curve. Definitions of assemblage metrics can be found in table 13. INTOL, intolerance; ABUN, abundance; EPT, Ephemeroptera, Plecoptera, Trichoptera; CH, Chironomidae; RICH, Richness; TOL, tolerance; p, percent; A full explanation of all invertebrate metrics can be found in Cuffney and others (2005). Tolerance and intolerance values are derived from U.S. Environmental Protection Agency, (1997).) 

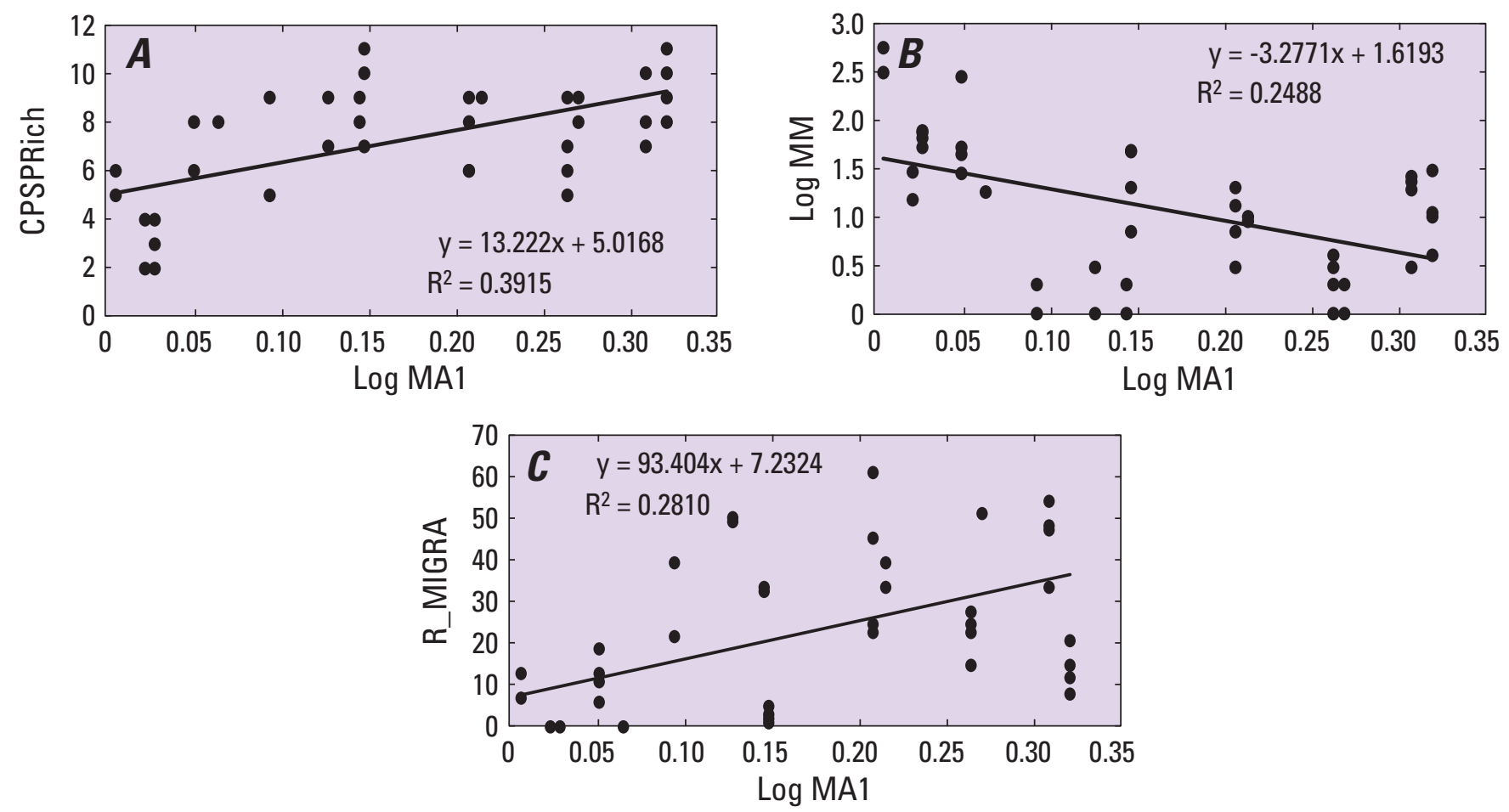

Figure 6. Fish-assemblage flow-ecology response relations between the mean of the daily mean flow values for the entire flow record (MA1, in cubic meters per second) and $(A)$ CPSPRich, $(B)$ MM, and $(C)$ R_MIGRA. (Definitions of assemblage metrics can be found in table 14. CPSP, Coastal Plain species; MM, mudminnow; MIGRA, migratory species; Species traits (for example, migratory species) evaluations are based on the approach presented in Goldstein and Meador (2005). Fish metrics (for example, CPSP) used in this study are generally based on the work of Crouse (2006).) 
by known anthropogenic effects. Without more intensive hydrologic modeling (for example, Kennen and others, 2008), it would be difficult to derive hydrographs that represent the Pinelands streams under pre-development conditions. That is, we were unable to derive simulated hydrographs that represent unimpacted flow conditions (as suggested by Poff and others, 2009) as part of this study. This limitation was overcome by using a variable-screening procedure of known anthropogenic drivers (that is, percent urban and agricultural land, SC, and $\mathrm{pH}$ ) to identify a subset of hydrologic variables (tables 8 and 11) for use in response-model development. This approach appeared to be highly successful in identifying hydrologic attributes with predictive power (for example, MA1 and MA12-23) that were not influenced by anthropogenic drivers.

Flow-ecology response relations between a reduced set of individual flow attributes and ecological measures were evaluated using Spearman's correlation and regression. Many hydrologic measures accounting for the duration and magnitude of low flows and the magnitude of average annual flows were significantly correlated with ecological response (tables 13 and 14). No frequency, timing, or rate-of-change attributes were retained for analysis as none met our screening criteria (that is, they are uncorrelated $(|r h o|<0.5000)$ with anthropogenic indicators such as urban and agricultural land use, $\mathrm{pH}$, and SC). Many invertebrate-assemblage metrics $(n=183)$ accounting for richness, abundance, and function of the aquatic-invertebrate assemblage were computed using the IDAS software (Cuffney and others, 2005); however, only a subset ( $\mathrm{n}=10$ invertebrate metrics) that met the screening criteria was retained for further analysis (table 13). In addition, a smaller suite of metrics $(\mathrm{n}=9)$, species $(\mathrm{n}=11)$, and species traits $(n=22)$ was aggregated for the fish assemblage. A subset of these fish measures meeting the above screening criteria was also retained for development of flow-ecology response relations (table 14).

The percentage abundance of intolerant taxa (INTOL_ABUNDp) was the invertebrate metric most strongly correlated with flow $(r h o=0.8628)$. All of the flow-ecology response relations between aquatic-invertebrate metrics and flow measures shown in table 13 were highly significant $(p<0.0001)$. Richness of Coastal Plain species (CPSPRich) was the fish metric most strongly correlated with flow $(r h o=0.7105)$ and all flow-ecology response relations between fish metrics and flow measures were significant at the $p<0.002$ level (table 14). In general, all fish and invertebrate response patterns followed positive or negative trends that would be expected given changes in stream hydrology or other environmental attributes, such as DO (fig. 4), that directly vary with streamflow. For example, as MA1 increased, there was an increase in the percent of intolerant invertebrate taxa (fig. 5A) and a concomitant decrease in tolerant taxa (fig. 5D). That is, as average annual flows of Pinelands streams increase, a higher proportion of intolerant and fewer tolerant taxa are present. In addition, as the average magnitude of monthly flows increased (MA1-average monthly flow), the total richness of taxa increased. The richness of EPT and Plecoptera taxa also was directly related to changes in the duration and magnitude of annual and low flows (table 13).

Abundance and richness of fish species appear to change in response to increases in the duration and magnitude of low-flow events (table 14). For example, as annual minimum flows for a 90-day moving average (that is, DL5) increased, total Coastal Plain richness increased. Higher minimum flows also appear to be highly significant in maintaining fish-community structure, especially spring and summer low flows (for example, ML5 and ML9-the mean of the minimum flows for May and September, respectively; table 14). Changes in functional response also were evident as the percentage of invertebrate gatherer-collectors (GC_Rich) and shredder abundance (SH_ABUND) increased with increasing average flows in May (MA16) and June (MA17), respectively (table 13).

Generally, all flow-ecology response relations developed during this study represent linear or slightly curvilinear responses (for example, figs. 4 and 5). No discrete "thresholds" or break points in the relations between flow and ecological response were apparent; however, some curves appeared to be asymptotic. For example, the abundance of intolerant invertebrates and total richness appear to increase with increasing annual flow, but level off at or near $1 \mathrm{~m}^{3} / \mathrm{s}$ (fig. 5A and C). Even in a restricted study area where all streams were of the same stream type or class (that is, Pinelands streams, or streams referred to as Class B in Kennen and others (2007)), which typically are stable streams with high base flow in the Coastal Plain, the high amount of variability seen in these data, especially those for fish, may have obscured our ability to identify any discrete thresholds in the aquatic-assemblage response patterns. Establishing empirically based flow-ecology response relations such as these, however, does provide insight into those aspects of flow that help to maintain the structural and functional integrity of aquatic assemblages and can be used for targeting the maintenance, restoration, or remediation of natural streamflow processes. 
Table 13. Aquatic-invertebrate assemblage metrics that were significantly correlated with the reduced set of hydrologic measures.

[Refer to table 11 or Kennen and others (2007) for hydrologic variable definitions. A detailed explanation of all invertebrate metrics can be found in Cuffney and others (2005). Functional feeding groups (for example, gatherer-collectors (GC) and shredders (SH)) are derived from Barbour and others (1999). Tolerance (TOL) and intolerance (INTOL) values are derived from U.S. Environmental Protection Agency (1997). <, less than; EPT, Ephemeroptera, Plecoptera, Trichoptera. See the highlighted blue box on the following page for additional explanatory material]

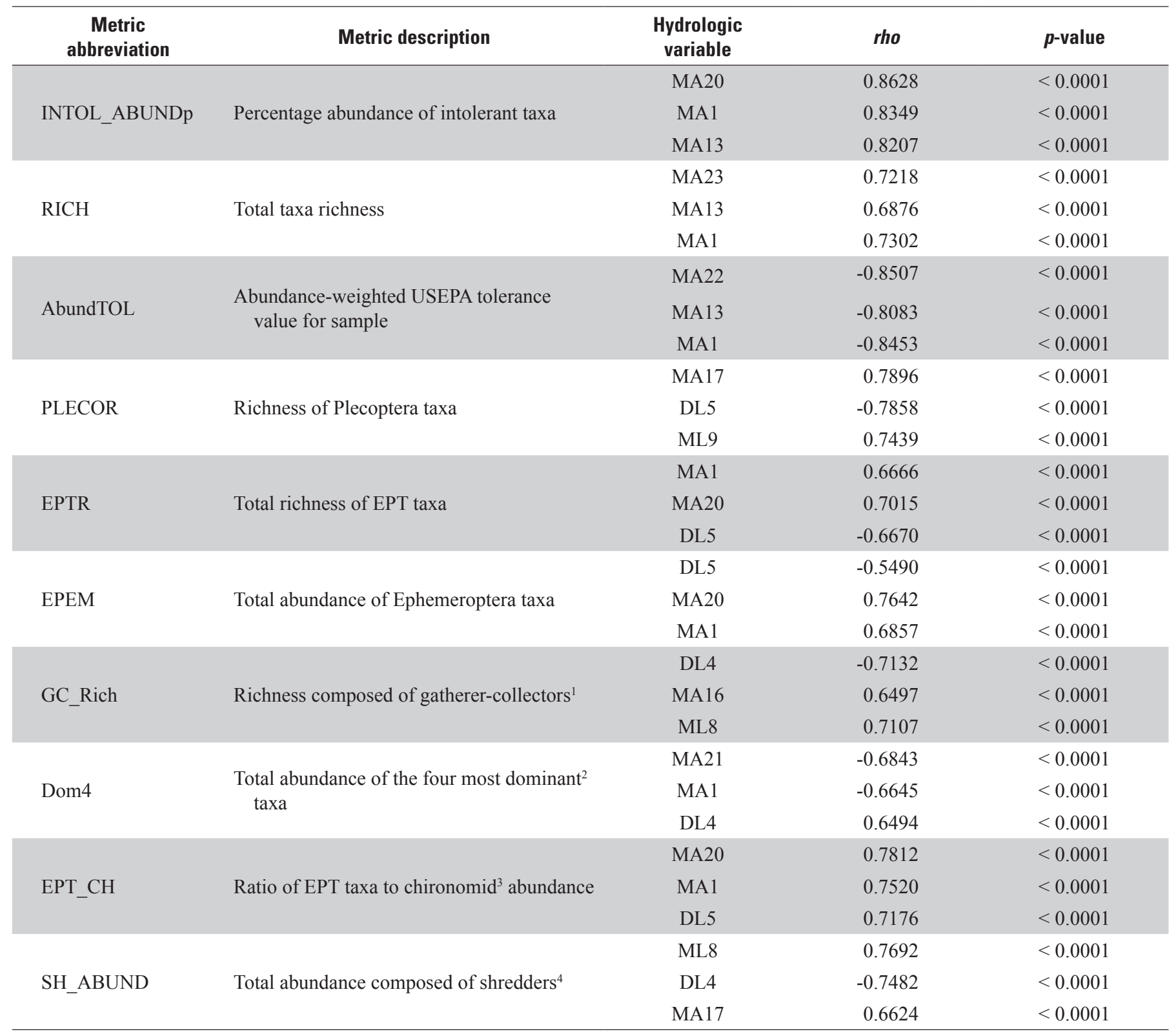

${ }^{1}$ Gatherer-collectors (GC) are aquatic organisms that feed primarily on fine pieces of decomposing particulate organic matter ( $<1$ millimeter in diameter) deposited in streams (for example, Hydropsyche sp., Caecidotea sp., Tribelos sp.) (Vannote and others, 1980; Merritt and Cummins, 1996).

${ }^{2}$ Dom 4 is the combined abundance of the four most dominant taxa in the sample; in Pinelands streams, Dom4 typically is a combination of the genera Hydropsyche sp., Caecidotea sp., Simulium sp., Tribelos sp., Rheotanytarsus sp., and Brachycentrus sp.

${ }^{3}$ Chironomidae $(\mathrm{CH})$ are small, non-biting fly larvae commonly referred to as midges that can be found in most aquatic habitats (for example, Rheotanytarsus sp., Polypedilum sp., and Tribelos sp.).

${ }^{4}$ Shredders $(\mathrm{SH})$ are aquatic organisms that chew primarily large pieces of decomposing vascular plant tissue ( $>1$ millimeter diameter) along with its associated microflora and fauna (for example, Pycnopsyche sp., Cricotopus sp., Polypedilum sp., and Leuctra sp.) (Vannote and others, 1980; Merritt and Cummins, 1996). 


\section{Aquatic-Invertebrate-Assemblage Metrics: Tolerance and Richness}

Tolerance values range from 0 (extremely sensitive organism) to 10 (tolerant organism). Tolerant taxa are considered to be tolerant of stream degradation (for example, Hydropsyche sp., Chironomus sp., Caecidotea sp., Tubificidae, Oecetis sp., and Pisidium sp.). A tolerant organism is one that is likely to be found in a site that has been altered by some type of environmental stressor (U.S. Environmental Protection Agency, 2006). Therefore, a sensitive taxon is one that tends to decline in abundance or occurrence probability along a defined stressor gradient (for example, streamflow modification, dissolved-oxygen concentration, etc.). In the Invertebrate Data Analysis System (IDAS) software, the tolerance values chosen for each taxon were based on values derived from the Mid-Atlantic Coastal Plain Work Group (U.S. Environmental Protection Agency, 1997), which included representatives from the states of New Jersey, Delaware, Maryland, North Carolina, and South Carolina. Ephemeroptera, Plecoptera, and Trichoptera (EPT) taxa are considered by most taxonomists to be highly sensitive to changes in stream condition (for example, E - Eurylophella sp., Stenonema sp., and Leptophlebiidae; P - Leuctra sp., Taeniopteryx sp., and Perlesta sp.; and T - Chimarra sp., Pycnopsyche sp., and Polycentropus sp.), and it is well established that the richness of EPT taxa varies proportionally with stream size, especially in smaller $\left(1^{\text {st }}\right.$ - through $4^{\text {th }}$ - order) streams (Paller and others, 2006).

Table 14. Fish-assemblage metrics, species, and species traits that are strongly correlated with the reduced set of hydrologic measures.

[Refer to tables 8 and 11 or Kennen and others (2007) for hydrologic variable definitions. Species traits (for example, migratory species) evaluations are based on the approach presented in Goldstein and Meador (2005). Fish metrics used in this study are generally based on the work of Crouse (2006). <, less than; MM, mudminnow; TPM, tadpole madtom; BBDS; black-banded sunfish; BSS, blue-spotted sunfish; CPSP, Coastal Plain species-species native to the Coastal Plain of NJ (for example, mud sunfish, mudminnow, creek chubsucker, pirate perch, and tadpole madtom); AcidTolSp, sunfish species considered to be acid tolerant (that is, bluespotted, banded, blackbanded, and mud sunfish); MIGRA, a reproductive category represented by migratory species-in this study, this trait is composed only of eel and creek chubsucker]

\begin{tabular}{|c|c|c|c|c|}
\hline $\begin{array}{c}\text { Metric } \\
\text { abbreviation }\end{array}$ & Metric description & $\begin{array}{l}\text { Hydrologic } \\
\text { variable }\end{array}$ & rho & $p$-value \\
\hline \multirow{2}{*}{ CPSPRich } & \multirow{2}{*}{ Richness of Coastal Plain species } & DL5 & 0.7105 & $<0.0001$ \\
\hline & & ML5 & 0.6872 & $<0.0001$ \\
\hline \multirow{2}{*}{ AcidTolSp } & \multirow{2}{*}{ Richness of acid-tolerant sunfish species } & DL1 & 0.5647 & $<0.0001$ \\
\hline & & ML16 & 0.5236 & 0.0003 \\
\hline \multirow{3}{*}{ TPM } & \multirow{3}{*}{ Total abundance of tadpole madtom } & DL5 & 0.6405 & $<0.0001$ \\
\hline & & MA16 & 0.6284 & $<0.0001$ \\
\hline & & ML5 & 0.5926 & $<0.0001$ \\
\hline MM & Total abundance of mudminnow & ML5 & 0.4762 & 0.0012 \\
\hline \multirow{3}{*}{ BBDS_BSS } & \multirow{3}{*}{ Total abundance of black-banded and blue-spotted sunfish } & MA16 & 0.7361 & $<0.0001$ \\
\hline & & ML9 & 0.4979 & 0.0007 \\
\hline & & DL1 & 0.6298 & $<0.0001$ \\
\hline \multirow{3}{*}{ R_MIGRA } & \multirow{3}{*}{$\begin{array}{l}\text { Total abundance of fish species that exhibit migratory behav- } \\
\text { ior for reproduction }\end{array}$} & MA16 & 0.6025 & $<0.0001$ \\
\hline & & DL5 & 0.5915 & $<0.0001$ \\
\hline & & MA1 & 0.5450 & 0.0002 \\
\hline
\end{tabular}




\section{Implications of Ecologically Relevant Flow Measures}

The flow-ecology response modeling effort presented in this report was used to identify hydrologic attributes that were directly related to differences in fish and aquatic-invertebrate assemblage complexity across a hydrologic gradient (tables 13 and 14). This effort was in direct response to the need to predict how increasing demand for water from the Kirkwood-Cohansey aquifer system (that is, water withdrawals for residential, commercial, and agricultural uses) resulting from increasing growth and development will affect aquatic assemblages in New Jersey Pinelands streams. Many of the hydrologic variables identified in this study accounted for a significant proportion of the variability and appeared to be a significant determinant of fish and invertebrate-assemblage structure and function - for example, the mean annual flow over the entire record (MA1) was highly correlated with many individual fish- and invertebrate-assemblage metrics (figs. 4 and 5). The annual minimum 90-day low flows (DL5) and the mean of the minimums of all September flow values over the entire record (ML9) were both significant predictors of changes in fish- and invertebrate-assemblage structure, respectively. The findings of this study are consistent with the results of other recent studies that point to changes in annual streamflow processes as being a significant driver of changes in assemblage structure and function (for example, Poff and Allan, 1995; Clausen and Biggs, 1997; Pusey and others, 2000; Bunn and Arthington, 2002; Kennen and Ayers, 2002; Kennen and others, 2010). In this study, however, a series of flow-ecology response relations was developed that directly relates variability in hydrologic processes to assemblage structure and function (see Poff and others, 2009) using bivariate linear and curvilinear response models (figs. 4 and 5). This approach has been strongly advocated by Arthington and others (2006), who suggest that once the types and degrees of flow modification have been determined for a specific stream type (that is, Pinelands streams in this study), the next crucial step is to develop empirically based quantitative relations between indicators of assemblage structure and function and streamflow processes.

It was postulated that variation in streamflow processes (that is, variation in one of the five main components of streamflow-magnitude, frequency, duration, timing, and rate of change) associated with continued water extraction would explain a significant portion of the variation in assemblage structure and function (that is, complexity) along a hydrologic gradient. The study findings provide evidence that many flow components, specifically duration and magnitude of low and annual flows, accounted for a significant portion of the variation in assemblage attributes. Even though recent studies have indicated that aquatic invertebrates appear to be resilient to stress associated with short-term reductions in streamflow (Miller and others, 2007; James and others, 2008), possibly utilizing the hyporheic zone as refugia (Dewson and others,
2007), the current study results may indicate that changes in flow processes could potentially modify natural assemblage complexity and push the aquatic assemblages beyond their capacity for resistance or resilience.

Periods of low flow tend to favor taxa that prefer slower velocities (Jowett, 1997) or those taxa that are more tolerant of stressors (for example, $\mathrm{O}_{2}$ depletion and increased water temperatures) associated with more slowly flowing water. In this study, fish- and invertebrate-assemblage structure across the hydrologic gradient appeared to be related to decreasing low-flow magnitudes. In particular, minimum flows, especially spring low flows (that is, ML5-the mean of the minimum flows for May), appeared to be important for maintaining fish-assemblage structure. The maintenance of spring-flow magnitude is known to be important for species adapted to a particular flow regime, especially those fishes that rely on flow cues for spawning, and support of crucial life-cycle stages (Grossman, 1982; Poff and Ward, 1989).

Timing, duration, and magnitude of annual and low-flow events are known to be important for the support of native stream communities (Poff and others, 1997) and are particularly relevant for synchronization of life-history processes. Lytle and Poff (2004) suggest that even though it is difficult to forecast annual flow events, it is likely that aquatic organisms adapt to the long-term averages, especially if such occurrences are in regions where there is some level of flow predictability (for example, annual spring flows or summer low flows in the northeastern United States). Synchronizing reproductive processes with annual or low-flow periods likely optimizes reproductive success and helps avoid high mortality rates during extreme events such as floods or droughts (Lytle, 2002; Boulton, 2003). In this study, annual flow variability-specifically variability across minimum monthly flows (for example, ML13)-was important for the fish assemblage (for example, mudminnows, table 14). This result may indicate that as the magnitude of low-flow processes is altered, some fish species with life-history and behavioral constraints that rely on annual flow patterns or fluctuations in flow for reproduction may become less abundant, whereas species with greater resilience to changes in natural stream variability will become more abundant. This response is exemplified by the significant relations established between taxa richness (RICH) and MA1 (fig. 5C), which show that a decrease in annual flow from 1.13 to $0.14 \mathrm{~m}^{3} / \mathrm{s}$ could reduce RICH by nearly half. Similarly, the abundance of intolerant taxa over the same range in annual flow could decrease by three-quarters (fig. 5A). Groundwater is the primary resource for support of streamflow in Pinelands systems (Rhodehamel, 1979; Zapecza, 1989) and likely buffers streamflow more during the spring than during summer low-flow periods, when aquifers and streamflows are most stressed. It can be postulated that exacerbation of low-flow periods in Pinelands streams due to increased water extraction may have a greater effect on the aquatic assemblages than it would during high-flow periods (also see Kennen and others, 2007), simply because less water is available in streams during low-flow periods. It is also possible that changes in 
average annual and monthly streamflow due to increased water extraction will result in a shift in aquatic-invertebrate species richness and abundance. This shift in assemblage structure along the hydrologic-response profile (for example, figs. 4 and 5) can be interpreted as an alteration of life-history or behavioral cues due to modified annual flow patterns. For example, emergence periods for more sensitive taxa (those taxa with a less plastic life histoy) like Ephemeroptera and Plecoptera (table 13) appeared to be affected by alterations in mean annual flow processes, whereas aquatic-invertebrate taxa that are more tolerant of changes in annual streamflow processes reflected a decrease in abundance in some response models (for example, AbundTOL; fig. 5D). DO concentrations in Pinelands streams appear to increase with increasing streamflow (fig. 4); thus, this covariation may also help to explain, in part, the strong relations seen between tolerance value and streamflow.

Even though the modeling approach used in this study attempted to eliminate the effects of anthropogenic degradation across the hydrologic-response profile, changes in water use to support population growth will likely alter the natural flow regime and have a measurable effect on native and endemic species. For example, abundance of native sunfish species including BSS and BBDS (BBDS_BSS; table 14) are responding to variation in the hydrologic regime and were highly related to the magnitude and duration of low flows, indicating that, in general, as increases in water use reduce streamflow, the abundance of native sunfish will likely decrease. This finding has important management implications for future water development in Pinelands streams. If the goal is to protect native fish species while simultaneously providing additional extraction for water-supply purposes, the magnitude and the duration of low flows may need to be maintained to ensure continued success of these species. Not all fish relations followed that pattern, however; for example, the abundance of eastern mudminnow (Umbra pygmaea), another native fish species, responded inversely and tended to decrease with increases in mean annual flow (fig. 6B). A large amount of scatter in these data was found; however, the downward trend was evident and a similar response was seen for annual monthly flows (table 14). A possible explanation for this inverse relation is that $\mathrm{MM}$ are tolerant of low DO, low $\mathrm{pH}$, and high temperatures, and tend to prefer areas of slowmoving backwater with vegetation and organic material. These types of habitats are common throughout small Coastal Plain streams as compared to larger streams with higher flow where MM are much less abundant and are often restricted primarily to the back-water areas.

The findings presented in this report are subject to some important limitations. A confounding difficulty encountered in this study was the unintended consequences of a sampling design that ultimately included underlying anthropogenic disturbance effects. In general, most of the sites sampled as part of this assessment were chosen because their basins contained minimal amounts of urban land use ( $\leq 24$ percent; see table 1$)$. However, results of multiple-regression models demonstrate that there was an underlying effect of urbanization, indicating that, even at relatively low levels, anthropogenic change can modify the hydrologic gradient and potentially alter interpretation of the assemblage response. Using a fairly rigorous screening criterion, those hydrologic and assemblage attributes that were directly responding to anthropogenic degradation as a result of land-use change were eliminated. This approach greatly enhanced the interpretive value of these data and helped to produce stronger and more scientifically defensible flow-ecology response models with the potential for management application.

Stronger predictive power was attained for development of invertebrate response models than fish models. Although significant, fish response models (fig. $6 \mathrm{~A}-\mathrm{C}$ ) tended to reflect more scatter and weaker R-squared values. This result may indicate that factors other than hydrology are influencing fishassemblage response and obfuscated the results. Availability of preferential habitats, such as emergent plants or undercut banks that provide cover and protection from predation, are likely key confounding factors (see Snelder and Lamouroux, 2010). Another possible limitation is the short-term duration of this study. Fish and aquatic-invertebrate assemblages represent the cumulative effects of hydrologic changes over time (Poff and others, 1997). Therefore, adaptive longer term studies would be useful in evaluating whether changes in water-use practices will actually result in a cumulative effect on aquatic assemblages. Long-term studies, however, may be impractical and difficult to implement given monetary constraints. Although rare, some exceptions do exist (see Daufresne and others, 2003; Humphries and others, 2008). The sampling network used in this study, however, was designed to evaluate projected changes in hydrologic processes through time by using stream-basin size as a surrogate for changes in flow, and represents a viable alternative for predicting the effects of hydrologic alteration in a relatively short timeframe. The significant flow-ecology response models identified in this study appear to indicate that variation in fish- and invertebrateassemblage structure could occur as a result of additional water extraction in the Pinelands.

Assessing potential variation in fish- and invertebrateassemblage structure along a hydrologic gradient, such as in this study, provides an opportunity for scientists and resource managers to focus on the most relevant hydrologic attributes and develop a management strategy that could include remediative, restorative, or preventive approaches, depending on the extent or degree of assemblage change or steepness of the slope of the flow-ecology response line or curve. That is, streams that have undergone minimal alterations in flow may need less remediation and more protection to avoid adverse consequences on stream biota, whereas streams whose flow is more modified and that have a steeper response curve represent systems whose remediative or restorative needs may be more immediate. Predictive bivariate linear and curvilinear response models, such as those presented in this study (figs. 4 and 5), can be used as a resource support tool to help managers and policy makers identify the point along the response 
function that fundamentally represents the "best-" or "worst-" case scenario for a particular level of water extraction and devise an approach for protecting, maintaining, or restoring stream hydrology and aquatic-assemblage structure and function. If sensitive or intolerant species were of interest, the point of maximum richness or abundance along the flowecology response curve or line (figs. 4 and 5) might be the basis for a management decision. For example, the abundance of intolerant invertebrates at $0.14 \mathrm{~m}^{3} / \mathrm{s}$ is approximately 10 ; however, at $1.0 \mathrm{~m}^{3} / \mathrm{s}$ abundance quadruples to more than 40 , whereas the abundance of highly tolerant taxa decreases by more than a third over the same flow range. Arthington and others (2006) suggest that an approach such as that presented in this report is needed to develop predictive models that reflect the ecological consequences of flow alteration and to inform scientific debate about ecosystem responses to flow modification and climate change (see also Baron and others, 2002; Naiman and others, 2002; Poff and others, 2003; Meyerson and others, 2005; Richter and others, 2006).

A recent paper by Poff and others (2009) has been instrumental in outlining a unified framework for developing regional environmental-flow standards called the Ecological Limits of Hydrologic Alteration (ELOHA). ELOHA builds directly upon the work of Arthington and others (2006), who challenged water scientists to establish and validate thresholds for flow measures using empirical biological data from natural or "reference" streams and flow-altered streams. The authors suggest that flow-ecology response relations be developed for a suite of ecological metrics across a gradient of flow regimes, similar to that used in this study. ELOHA, however, is designed to support comprehensive regional flow management and strives to synthesize available scientific information into ecologically based and socially acceptable goals and standards for management of environmental flows. Key steps are outlined to help environmental-flow practitioners develop relations between flow alteration and ecological response. These include (1) building a sound hydrologic foundation of baseline hydrographs for ungaged streams using a flow-modeling tool (for example, Kennen and others, 2008); (2) employing a set of ecologically relevant flow attributes to classify streams into distinctive flow-regime types (for example, Olden and Poff, 2003; Kennen and others, 2007; Armstrong and others, 2008); (3) determining the deviation of current-condition flows from baseline-condition flows (for example, Esralew and Baker, 2008); and (4) developing flow-ecology response relations. The approach presented in this report is consistent with ELOHA and incorporates most of the major steps. The final step outlined in ELOHA-directly establishing flowecology response relations is accomplished by using a class of Pinelands streams where USGS continuous-record gaging stations have been instrumented and (or) staff gages have been established (see Hydrologic Assessment section). These flow-ecology response relations can be further used to support flow-management strategies by providing stream-type-specific empirical results to guide the implementation of remediation efforts or to determine the point along a specific response curve representing the greatest loss of native Pinelands species or assemblage complexity, and subsequently manage projected development to minimize these changes. In addition, these empirical relations can be used to guide the development of State environmental-flow programs whether they are descriptive or based on ecologically relevant flow measures such as those presented in the Hydroecological Integrity Assessment Process (Kennen and others, 2007) or the Indicators of Hydrologic Alteration (Richter and others, 1997). Ultimately, such relations can inform water-resource managers, planners, and policy makers on the suite of hydrologic indices that may be most effective for use in setting environmental-flow standards in and near the Pinelands protection area.

\section{Summary}

Increases in water demand associated with population growth in the Pinelands region of southern New Jersey are likely to have a direct effect on stream hydrology, including reductions in streamflow associated with increased water extraction. State resource-management agencies are mandated by law to ensure that increased consumptive water use does not adversely affect the unique habitats and ecology of the Pinelands area. Although many aquatic fauna have shown resilience and resistance to short-term changes in flows associated with water withdrawals, sustained effects associated with ongoing water development are not well understood. Therefore, the U.S. Geological Survey sampled forty-three 100-m-long stream reaches to evaluate whether changes in water demand associated with population growth and changes in land-use practices will have a measurable effect on the ecology of the Pinelands. Fourteen native and several non-native fish species and more than 125 invertebrate taxa were collected at the 43 New Jersey Pinelands streams. Additionally, more than 445 environmental variables (that is, hydrologic, water-quality, and physical variables associated with each stream reach) were summarized for this study. A combination of Spearman rank correlation, regression, and multivariate statistical methods were used to identify potential linkages among environmental factors and determine the significant hydrologic attributes accounting for fish- and invertebrateassemblage response.

The findings of this study indicate that variation in the composition of fish and invertebrate assemblages could occur as a consequence of alterations in streamflow processes resulting from increased water extraction from Pinelands basins. The hydrologic characteristics that were found to be most important in determining aquatic-assemblage composition included changes in annual and low flows. Many of these attributes were good predictors of differences in assemblage complexity. Flow-ecology response relations were different for fish and invertebrate assemblages. Even though the response relations developed for this study followed upward or downward trends that would be expected as a result of shifts in natural 
stream hydrology, stronger and more significant flow-ecology response models were developed for the invertebrate assemblage. In general, the ecological-response models predict that variation in the magnitude and duration of average annual and low flows are related to the variation in aquatic-assemblage structure across the hydrologic-response profile. This result may indicate that as the Pinelands become more developed and water extraction increases to support population growth, the streams will have a reduced capacity to adequately buffer these effects and aquatic-assemblage structure and function could be compromised. Flow alterations, especially alteration of spring flows, which are necessary for spawning, recruitment, and emergence of many aquatic species, have been consistently found to directly affect stream assemblages. Reductions in streamflow also can greatly reduce available habitat and can directly affect water temperatures, oxygen levels, and primary productivity. In addition, alterations in the flow regime may affect aquatic species that have life-history strategies that are adapted to the natural flow patterns. Therefore, as water extraction along the periphery of the Pinelands protection area continues to increase, the resulting hydrologic alterations likely will have a measurable effect on fish- and invertebrate-assemblage structure and function. Implementation of longer term studies would facilitate the evaluation of ongoing adjustments in assemblage structure resulting from hydrologic alteration.

The many bivariate linear and curvilinear fish- and invertebrate-response models presented in this report could be used as the basis for setting flow maxima or minima that would protect biotic complexity and native Pinelands species and could be used as reference points for imposing or relaxing water-allocation constraints. In addition, results of hydrologic modeling could be used to develop a subset of streamflowchange scenarios that could be applied to the flow-ecology response models developed in this study to predict the effects of potential water extraction on the abundance and complexity of fish and aquatic-invertebrate assemblages throughout the Pinelands.

\section{Acknowledgments}

The authors thank the many individuals of the New Jersey Pinelands Commission, especially Robert Zampella, John Bunnell, Kim Laidig, Nicholas Procopio, and Kimberly Spiegel, who dedicated staff resources and time to assist with field work, including the collection of fish samples, canopy and in-stream plant-cover measurements, and water-quality assessment, that was an integral part of this study. Additional field support from Pamela Reilly, Jason Lewis, and Holly Weyers of the USGS is immensely appreciated. We are indebted to the many individuals who carried out the continuous-record and staff-gage installation and monitoring throughout the duration of this study, including Blaine White, Ken Hayes, Rick Edwards, Andy Watson, Jason Shvanda, Tom Moffett, John Trainor, Brian Painter, and Aric Vanselous. Special thanks is due to Kara Watson of the USGS for her assistance with GIS data analysis and mapping. Thanks also to Gary Lester and his very talented staff at EcoAnalysts for processing all the Pinelands benthic samples and identifying the invertebrates to the lowest possible taxonomic level. Evan Hornig and Robert Reiser of the USGS and John Bunnell of the New Jersey Pinelands Commission, respectively, provided many helpful suggestions that greatly improved this report.

\section{References Cited}

Allan, J.D., 1995, Stream ecology: Structure and function of running waters: Chapman and Hall, $400 \mathrm{p}$.

Armstrong, D.S., Parker, G.W., and Richards, T.A., 2001, Assessment of habitat, fish communities, and streamflow requirements for habitat protection, Ipswich River, Massachusetts, 1998-99: U.S. Geological Survey WaterResources Investigations Report 01-4161, 72 p. (Also available at http://pubs.er.usgs.gov/usgspubs/wri/wri20014161.)

Armstrong, D.S., Parker, G.W., and Richards, T.A., 2008, Characteristics and classification of least altered streamflows in Massachusetts: U.S. Geological Survey Scientific Investigations Report 2007-5291, 113 p., plus CD-ROM. (Also available at http://pubs.usgs.gov/sir/2007/5291/.)

Arthington, A.H., Bunn, S.E., Poff, N.L., and Naiman, R.J., 2006, The challenge of providing environmental flow rules to sustain river ecosystems: Ecological Applications, v. 16, p. 1311-1318. (Also available at $h t t p: / / d x . d o i$. org/10.1890/1051-0761(2006)016[1311:TCOPEF]2.0 CO;2).

Arthington, A.H., King, J.M., O'Keefe, J.H., Bunn, S.E., Day, J.A., Pusey, B.J., Bluhdorn, D.R., and Thame, R., 1991, Development of an holistic approach for assessing environmental flow requirements of riverine ecosystems, in Pigram, J.J., and Hooper, B.A., eds. Water allocation for the environment: Proceedings of an international seminar and workshop: Armidale, Australia, University of New England,The Centre for Water Policy Research, p. 69-76.

Barbour, M.T., Gerritsen, J., Snyder, B.D., and Stribling, J.B., 1999, Rapid bioassessment protocols for use in streams and wadeable rivers: Periphyton, benthic macroinvertebrates, and fish (2d ed.): U.S. Environmental Protection Agency Report, EPA 841-B-99-002, 226 p. (Also available at http:// www.epa.gov/owow/monitoring/rbp/.)

Baron, J.S., Poff, N.L., Angermeier, P.L., Dahm, C.N., Gleick, P.H., Hairston, N.G., Jr., Jackson, R.B., Johnston, C.A., Richter, B.G., and Steinman, A.D., 2002, Meeting ecological and societal needs for freshwater: Ecological Applications, v. 12, p. 1247-1260. (Also available at $h t t p: / / d x . d o i$. org/10.1890/1051-0761(2002)012[1247:MEASNF]2.0 .CO;2). 
Biggs, B.J.F., Nikora, V.I., and Snelder, T.H., 2005, Linking scales of flow variability to lotic ecosystem structure and function: River Research and Applications, v. 21, p. 283-298 (Also available at $h t t p: / / d x . d o i . o r g / 10.1002 /$ rra.847).

Blinn, D.W., Shannon, J.P., Stevens, L.E., and Carder, J.P., 1995, Consequences of the fluctuating discharge for lotic communities: Journal of the North American Benthological Society, v. 14, no. 2, p. 233-248 (Also available at http://dx.doi.org/10.2307/1467776).

Boulton A.J., 2003, Parallels and contrasts in the effects of drought on stream macroinvertebrate assemblages: Freshwater Biology, v. 48, p. 1173-1185 (Also available at http://dx.doi.org/10.1046/j.1365-2427.2003.01084.x).

Buchanan, T.J., and Somers, W.P., 1969, Discharge measurements at gaging stations: USGS-TWRI book 3, chap. A8, $65 \mathrm{p}$.

Bunn, S.E., and Arthington, A.H., 2002, Basic principles and ecological consequences of altered flow regimes for aquatic biodiversity: Environmental Management, v. 30, no. 4, p. 492-507 (Also available at $h t t p: / / d x$.doi.org/10.1007/ s00267-002-2737-0).

Clarke, K.R., and Gorley, R.N., 2006, PRIMER v6: Users Manual/Tutorial PRIMER-E: Plymouth, England, 190 p.

Clarke, K.R., and Warwick, R.M., 2001, Change in marine communities: An approach to statistical analysis and interpretation, (2d edition.) PRIMER-E: Plymouth, England.

Clausen, B., and Biggs, B.J.F., 1997, Relationships between benthic biota and hydrological indices in New Zealand streams: Freshwater Biology, v. 38, p. 327-342 (Also available at $h t t p: / / d x . d o i . o r g / 10.1046 / j .1365-$ 2427.1997.00230.x).

Crouse, S.M., 2006, Development of a fish index of biotic integrity for wadeable streams of New Jersey's lower Delaware River drainage: unpublished master's thesis, East Stroudsburg, Penn., East Stroudsburg University, 133 p.

Cuffney, T.F., 2003, User manual for the National Water-Quality Assessment Program Invertebrate Data Analysis System (IDAS) software: Version 3.0: U.S. Geological Survey Open-File Report 03-172, 103 p. (Also available at http://pubs.er.usgs.gov/usgspubs/ofr/ofr03172.)

Cuffney, T.F., Bilger, M.D., and Haigler, A.M., 2007, Ambiguous taxa: Effects on the characterization and interpretation of invertebrate assemblages: Journal of the North American Benthological Society, v. 26, p. 286-307 (Also available at http://dx.doi.org/10.1899/0887-3593(2007)26[286:ATEOT C]2.0.CO;2).
Cuffney, T.F., Zappia, H., Giddings, E.M.P., and Coles, J.F., 2005, Effects of urbanization on benthic macroinvertebrate assemblages in contrasting environmental settings: Boston, Massachusetts; Birmingham, Alabama; and Salt Lake City, Utah: American Fisheries Society Symposium 2005, v. 47, p. 361-407.

Daufresne, M., Roger, M.C., Capra, H., and Lamouroux, N., 2003, Long-term changes within the invertebrate and fish communities of the Upper Rhone River: Effects of climatic factors: Global Change Biology, v. 10, p. 124-140 (Also available at $h t t p: / / d x . d o i . o r g / 10.1046 / j .1529-$ 8817.2003.00720.x).

Dewson, Z.S., James, A.B.W., and Death, R.G., 2007, A review of the consequences of decreased flow for instream habitat and macroinvertebrates: Journal of the North American Benthological Society, v. 26, p. 401-415 (Also available at $h t t p: / / d x$.doi.org/10.1111/j.1365-2427.2006.01682.x).

Esralew, R.A., and Baker, R.J., 2008, Determination of baseline periods of record for selected streamflow-gaging stations in New Jersey for determining Ecologically Relevant Hydrologic Indicies (ERHI): U.S. Geological Survey Scientific Investigations Report 2008-5077, 70 p. (Also available at $h t t p: / / p u b s . u s g s . g o v /$ sir/2008/5077/pdf/sir20085077.pdf.)

Farlekas, G.M., Nemickas, Bronius, and Gill, H.E., 1976, Geology and ground-water resources of Camden County, New Jersey: U.S. Geological Survey Water-Resources Investigations 76-76, $146 \mathrm{p}$.

Fitzpatrick, F.A., Waite, I.R., D’Arconte, P.J., Meador, M.R., Maupin, M.A., and Gurtz, M.E., 1998, Revised methods for characterizing stream habitat in the National WaterQuality Assessment Program: U.S. Geological Survey Water-Resources Investigations Report 98-4052, 67 p. (Also available at $h t t p: / / p u b s . u s g s . g o v / w r i / w r i 984052 / p d f / w r i 98-$ 4052.pdf.)

Goldstein, R.M., and Meador, M.R., 2005, Multilevel assessment of fish species traits to evaluate habitat degradation in streams of the upper Midwest: North American Journal of Fisheries Management, v. 25, p. 180-194 (Also available at http://dx.doi.org/10.1577/M04-042.1).

Grossman, G.D., 1982, Dynamics and organization of a rocky intertidal fish assemblage: The persistence and resilience of taxocene structure: American Naturalist, v. 119, p. 611-637. (Also available at http://www.jstor.org/ stable/2461182? origin $=J S T O R-p d f$.)

Hastings, R.W., 1984, The fishes of the Mullica River, a naturally acid water system of the New Jersey Pine Barrens: Bulletin of the New Jersey Academy of Science, v. 29, p. 9-23. 
Henriksen, J.A., Heasley, J., Kennen, J.G., and Nieswand, S.P., 2006, Users' manual for the Hydroecological Integrity Assessment Process software (including the New Jersey Assessment Tools): U.S. Geological Survey Open-File Report 2006-1093, 71 p. (Also available at http://pubs. er.usgs.gov/usgspubs/ofr/ofr20061093.)

Hirsch, R.M., 1982, A comparison of four streamflow record extension techniques: Water Resources Research, v. 18, no. 4, p. 1081-1088.

Humphries, P., Brown, P., Douglass, J., Pickworth, A., Strongman, R., Hall, K., and Serafini, L., 2008, Flow-related patterns in abundance and composition of the fish fauna of a degraded Australian lowland river: Freshwater Biology, v. 53, p. 789-813 (Also available at http://dx.doi. org/10.1111/j.1365-2427.2007.01904.x).

Humphries, P., King, A.J., and Koehn, J.D., 1999, Fish, flows, and floodplains: Links between freshwater fishes and their environment in the Murray-Darling River system, Australia: Environmental Biology of Fishes, v. 56, p. 129-151 (Also available at $h t t p: / / d x$.doi.org/10.1023/A:1007536009916).

Hynes, H.B.N, 1970, The ecology of running waters: Toronto, Canada, University of Toronto Press, 555 p.

Jackson, D.A., 1993, Stopping rules in principal components analysis: A comparison of heuristical and statistical approaches: Ecology, v. 74, p. 2204-2214 (Also available at $h t t p: / / d x$.doi.org/10.2307/1939574).

James, A.B.W., Dewson, Z.E., and Death, R.G., 2008, Do stream invertebrates use instream refugia in response to severe short-term flow reduction in New Zealand streams?: Freshwater Biology, v. 53, p. 1316-1334 (Also available at http://dx.doi.org/10.1111/j.1365-2427.2008.01969.x).

Jenkins, R.E., and Burkhead, N.M., 1993, Freshwater fishes of Virginia: Bethesda, Maryland, American Fisheries Society, $1079 \mathrm{p}$.

Jowett, I.G., 1997, Environmental effects of extreme flows, in Mosley, M.P., and Pearson, C.P., eds., Floods and droughts: The New Zealand experience: Christchurch, New Zealand, Caxton Press, p. 104-116.

Kennen, J.G., and Ayers, M.A., 2002, Relation of environmental characteristics to the composition of aquatic assemblages along a gradient of urban land use in New Jersey, 1996-98: U.S. Geological Survey Water-Resources Investigations Report 02-4069, 77 p. (Also available at http://pubs.usgs. gov/wri/wri024069/pdf/wri024069.pdf.)

Kennen, J.G., Chang, M., and Tracy, B.H., 2005. Effects of landscape change on fish assemblage structure in a rapidly growing metropolitan area in North Carolina, USA, in Brown, L.R., Gray, R.H., Hughes, R.M., and Meador, M.R., eds., Effects of urbanization on stream ecosystems. American Fisheries Society, Symposium 47, Bethesda, Maryland, p. 39-52.
Kennen, J.G., Henriksen, J.A., and Nieswand, S.P., 2007, Development of the Hydroecological Integrity Assessment process for determining environmental flows for New Jersey streams: U.S. Geological Survey Scientific Investigations Report 2007-5206, 55 p. (Also available at $h t t p: / /$ pubs.usgs.gov/sir/2007/5206/pdf/sir2007-5206-508.pdf.)

Kennen, J.G., Kauffman, L.J., Ayers, M.A., and Wolock, D.M., 2008, Use of an integrated flow model to estimate ecologically relevant hydrologic characteristics at stream biomonitoring sites: Ecological Modelling, v. 211, p. 57-76 (Also available at $h t t p: / / d x . d o i . o r g / 10.1016 / j$. ecolmodel.2007.08.014).

Kennen, J.G., Murray, K.R., and Beaulieu, K.M., 2010, Determining hydrologic factors that influence stream macroinvertebrate assemblages in the northeastern U.S. Ecohydrology, v. 3, p. 88-106 (Also available at $h t t p: / / d x$.doi.org/10.1002/ eco.99).

King, R.S., Baker, M.E., Whigham, D.F., Weller, D.E., Jordan, T.E., Kazyak P.F., and Hurd, M.K., 2005, Spatial consideration for linking watershed land cover to ecological indicators in streams: Ecological Applications, v. 15, p. 137-153 (Also available at $h t t p: / / d x$.doi.org/10.1890/04-0481).

Klein, R.D., 1979, Urbanization and stream quality impairment: Water Resources Bulletin, v. 15, p. 948-963 (Also available at $h t t p: / / d x$.doi.org/10.1111/j.1752-1688.1979. tb01074.x).

Konrad, C.P., and Booth, D.B., 2005, Hydrologic changes in urban streams and their ecological significance: in Brown, L.R., Gray, R.H., Hughes, R.M., and Meador, M.R., eds., Effects of urbanization on stream ecosystems: American Fisheries Society, Symposium 47, Bethesda, Maryland, p. $157-177$.

Kozak, A., and Kozak, R., 2003, Does cross validation provide additional information in the evaluation of regression models?: Canadian Journal of Forest Research, v. 33, p. 976-987 (Also available at http://dx.doi.org/10.1139/ x03-022).

Legendre, P., and Legendre, L., 1998, Numerical ecology: 2d English edition, Amsterdam, Elsevier, 853 p.

Lytle, D.A., 2002, Flash floods and aquatic insect life history evolution: Evaluation of multiple models: Ecology, v. 83, p. 370-385 (Also available at $h t t p: / / d x . d o i$. org/10.2307/2680021).

Lytle D.A., and Poff, N.L., 2004, Adaptation to natural flow regimes: Trends in Ecology, and Evolution, v. 19, p. 94-100 (Also available at $h t t p: / / d x . d o i . o r g / 10.1016 / j$. tree.2003.10.002).

Maitland, P.S., 1994, The ecology of the River Endrick: Present status and change since 1960: Hydrobiologia, v. 290, p. 105-120 (Also available at http://dx.doi.org/10.1007/ BF00008961). 
Mathews, R., 2005, A six-step framework for ecologically sustainable water management: Universities Council on Water Resources: Journal of Contemporary Water Research and

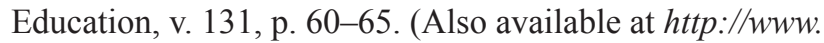
ucowr.siu.edu/updates/131/12_matthews.pdf).

Maxted, J.R., Barbour, M.T., Gerritsen, J., Poretti, V., Primrose, N., Silva, A., Penrose, D., and Renfrow, R., 2000, Assessment framework for mid-Atlantic coastal plain streams using benthic macroinvertebrates: Journal of the North American Benthological Society, v. 19, p. 128-144 (Also available at $h t t p: / / d x$.doi.org/10.2307/1468286).

McCune, B., and Grace, J.B., 2002, Analysis of ecological communities: Gleneden Beach, Oregon, MjM Software Design, $256 \mathrm{p}$.

McKay, S.F., and King, A.J., 2006, Potential ecological effects of water extraction in small, unregulated streams: River Research and Applications, v. 22, p. 1023-1037 (Also available at $h$ ttp://dx.doi.org/10.1002/rra.958).

Merritt, R.W., and Cummins, K.W., 1996, An introduction to the aquatic insects of North America, 3d ed.: Dubuque, Iowa, Kendall/Hunt Publishing Company, 772 p.

Meyerson, L.A., Baron, J., Melillo, J., Naiman, R.J., O'Malley, R.I., Orians, G., Palmer, M.A., Pfaff, A.S.P., Running, S.W., and Sala, O.E., 2005. Aggregate measures of ecosystem services: Can we take the pulse of nature?: Frontiers in Ecology and the Environment, v. 3, p. 56-59 (Also available at $h t t p: / / d x$.doi.org/10.2307/3868445).

Miller, S.W., Wooster, D., and Li, J., 2007, Resistance and resilience of macroinvertebrates to irrigation water withdrawals: Freshwater Biology, v. 52, p. 2494-2510 (Also available at $h t t p: / / d x$.doi.org/10.1111/j.13652427.2007.01850.x).

Morgan, M.D., 1984, Acidification of headwater streams in the New Jersey Pinelands: A reevaluation: Limnology and Oceanography, v. 29, no. 6, p. 1259-1266.

Moulton, S.R., II, Kennen, J.G., Goldstein, R.M., and Hambrook, J.A., 2002, Revised protocols for sampling algal, invertebrate, and fish communities as part of the National Water-Quality Assessment Program: U.S. Geological Survey Open-File Report 02-150, 87 p. (Also available at http://water.usgs.gov/nawqa/protocols/OFR02-150/OFR02150.pdf.)

Moyle, P.B., and Light, T., 1996, Biological invasions of fresh water: Empirical rules and assembly theory: Biological Conservation, v. 78, p. 149-161 (Also available at $h t t p: / /$ dx.doi.org/10.1016/0006-3207(96)00024-9).

Naiman, R.J., Bunn, S.E., Nilsson, C., Petts, G.E., Pinay, G., and Thompson, L.C., 2002, Legitimizing fluvial ecosystems as users of water: An overview: Environmental Management, v. 30, p. 455-467 (Also available at $h t t p: / / d x . d o i$. org/10.1007/s00267-002-2734-3).
Nelson, J.S., Crossman, E.J., Espinosa-Perez, H., Findley, L.T., Gilbert, C.R., Lea, R.N., and Williams, J.D., 2004, Common and Scientific Names of Fishes from the United States, Canada, and Mexico (6 $6^{\text {th }}$ ed.): Bethesda Maryland, American Fisheries Society, Special Publication 29, 386 p.

Olden J.D., and Jackson, D.A., 2000, Torturing data for the sake of generality: How valid are our regression models?: Ecoscience, v. 7, p. 501-510.

Olden, J.D., and Poff, N.L., 2003, Redundancy and the choice of hydrologic indices for characterizing streamflow regimes: River Research and Applications, v. 19, p. 101-121 (Also available at http://dx.doi.org/10.1002/ rra.700).

Paller, M.H., Specht, W.L., and Dyer, S.A., 2006, Effects of stream size on taxa richness and other commonly used benthic bioassessment metrics: Hydrobiologia, v. 568, p. 306-316 (Also available at $h t t p: / / d x$.doi.org/10.1007/ s10750-006-0208-y).

Perry, S.A., and Perry, W.B., 1986, Effects of experimental flow regulation on invertebrate drift and stranding in the Flathead and Kootenai Rivers: Hydrobiologia, v. 134, p. 171-182 (Also available at http://dx.doi.org/10.1007/ BF00006739).

Plafkin, J.L., Barbour, M.T., Porter, K D., Gross, S.K., and Hughes, R.M., 1989, Rapid bioassessment protocols for use in streams and rivers: Benthic macroinvertebrates and fish: U.S. Environmental Protection Agency, EPA/444/489/001, variously paged.

Poff, N.L., and Allan, J.D., 1995, Functional organization of stream fish assemblages in relation to hydrological variability: Ecology, v. 76, p. 606-627 (Also available at http://dx.doi.org/10.2307/1941217).

Poff, N.L., Allan, J.D., Bain, M.B., Karr, J.R., Prestegaard, K.L., Richter, B.D., Sparks, R.E., and Stromberg, J.C., 1997, The natural flow regime: A paradigm for river conservation and restoration: BioScience, v. 47, p. 769-784 (Also available at $h t t p: / / d x$.doi.org/10.2307/1313099).

Poff, N.L., Allan, J.D., Palmer, M.A., Hart, D.D., Richter, B.D., Arthington, A.H. Rogers, K.H., Meyer, J.L., and Stanford, J.A., 2003, River flows and water wars: Emerging science for environmental decision making: Frontiers in Ecology and the Environment, v. 1, p. 298-306 (Also available at $h t t p: / / d x$.doi.org/10.2307/3868090).

Poff, N.L., Olden, J.D., Vieira, N.K.M., Finn, D.S., Simmons, M.P., and Kondratieff, B.C., 2006, Functional trait niches of North American lotic insects: Traits-based ecological applications in light of phylogenetic relationships: Journal of the North American Benthological Society, v., 25, no. 4, p. 730-755 (Also available at http:// dx.doi.org/10.1899/0887-3593(2006)025[0730:FTNONA] 2.0.CO;2). 
Poff, N.L., Richter, B.D., Arthington, A.H., Bunn, S.E., Naiman, R.J., Kendy, E., Acreman, M., Apse, C., Bledsoe, B.P., Freeman, M.C., Henrik-sen, J.A., Jacobson, R.B., Kennen, J.G., Meritt, D.M., O’Keeffe, J., Olden, J.D., Rogers, K.H., Tharme, R.E., and Warner, A.T., 2009, The Ecological Limits of Hydrologic Alteration (ELOHA): A new framework for developing regional environmental flow standards: Freshwater Biology: Published Online: Sep 22009 9:07 PM (Also available at http://dx.doi. org/10.1111/j.1365-2427.20 09.02204.x).

Poff, N.L., and Ward, J.V., 1989, Implications of streamflow variability and predictability for lotic community structure: A regional analysis of streamflow patterns: Canadian Journal of Fisheries and Aquatic Sciences, v. 46, p. 1805-1818 (Also available at http://dx.doi.org/10.1139/f89-228).

Postel, S.A., 2000, Entering an era of water scarcity: The challenges ahead: Ecological Applications, v. 10, p. 941-948 (Also available at http://dx.doi.org/10.1890/10510761(2000)010[0941:EAEOWS]2.0.CO;2).

Power, M.E., Dietrich, W.E., and Finlay, J.C., 1996, Dams and downstream aquatic biodiversity: Potential food web consequences of hydrologic and geomorphic change: Environmental Management, v. 20, p. 887-895 (Also available at $h t t p: / / d x$.doi.org/10.1007/BF01205969).

Pusey, B.J., Arthington, A.H., and Read, M.G., 1993, Spatial and temporal variation in fish assemblage structure in the Mary River, south-east Queensland: The influence of habitat structure: Environmental Biology of Fishes, v. 37, p. 355-380.

Pusey, B.J., Arthington, A.H., and Read, M.G., 1995, Species richness and spatial variation in fish assemblage structure in two rivers of the Wet Tropics of Northern Queensland, Australia: Environmental Biology of Fishes, v. 42, p.191-199 (Also available at http://dx.doi.org/10.1007/ BF00001996).

Pusey, B.J., Kennard, M.J., and Arthington, A.H., 2000, Discharge variability and the development of predictive models relating stream fish assemblage structure to habitat in northeastern Australia: Ecology of Freshwater Fish, v. 9, p. 30-50 (Also available at http://dx.doi.org/10.1034/j.16000633.2000.90105.x).

Reynolds, J.B., 1996, Electrofishing, in Murphy, B.R., and Willis, D.W., eds., Fisheries techniques, ( $2 \mathrm{~d}$ ed.): Bethesda, Maryland, American Fisheries Society, p. 221-253.

Rhodehamel, E.C., 1970, A hydrologic analysis of the New Jersey Pine Barrens Region: New Jersey Division of Water Policy Water Resources Circular No. 22, 35 p.

Rhodehamel, E.C., 1979, Geology of the Pine Barrens of New Jersey, in Forman, R.T.T., ed., Pine Barrens ecosystem and landscape: New York Academic Press, p. 36-60.
Richter, B.D., Baumgartner, J.V., Powell, J., and Braun, D.P., 1996, A method for assessing hydrologic alteration within ecosystems: Conservation Biology, v. 10, p. 1163-1174 (Also available at http://dx.doi.org/10.1046/j.15231739.1996.10041163.x).

Richter, B.D., Baumgartner, J.V., Wigington, R., and Braun, D.P., 1997, How much water does a river need?: Freshwater Biology, v. 37, p. 231-249 (Also available at http:// dx.doi.org/10.1046/j.1365-2427.1997.00153.x).

Richter, B.D., Warner, A.T., Meyer, J.L., and Lutz, K., 2006, A collaborative and adaptive process for developing environmental flow recommendations: River Research and Applications, v. 22, p. 297-318 (Also available at http://dx.doi. org/10.1002/rra.892).

Riley, A.L., 1998, Restoring streams in cities-A guide for planners, policy makers, and citizens: Washington, D.C., Island Press, $423 \mathrm{p}$.

Robinson, K.W., Flanagan, S.M., Ayotte, J.D., Campo, K.W., Chalmers, A., Coles, J.F, and Cuffney, T.F., 2004, Water quality in the New England Coastal Basins, Maine, New Hampshire, Massachusetts, and Rhode Island, 1999-2001: U.S. Geological Survey Circular 1226, 38 p. (Also available at http://pubs.usgs.gov/circ/2004/1226/.)

Roy, A.H., Freeman, M.C., Freeman, B.J., Wenger, S.J., Ensign, W.E., and Meyer, J.L., 2005, Investigating hydrological alteration as a mechanism of fish assemblage shifts in urbanizing streams: Journal of the North American Benthological Society, v. 24, p. 656-678 (Also available at http://dx.doi.org/10.1899/0887-3593(2005)0241 [0656:IHAAAM $\backslash$ ]2.0.CO;2).

Roy, A.H., Rosemond, A.D., Paul, M.J., Leigh, D.S., and Wallace, J.B., 2003, Stream macroinvertebrate response to catchment urbanisation (Georgia, U.S.A.): Freshwater Biology, v. 48, p. 1-18 (Also available at http://dx.doi. org/10.1046/j.1365-2427.2003.00979.x).

SAS Institute Inc., 1989, SAS/STAT ${ }^{\circledR}$ users guide, version 6, 4th ed., v. 2: Cary, North Carolina, SAS Institute Inc., 848 p.

SAS Institute Inc., 1991, SAS ${ }^{\circledR}$ system for regression (2 ${ }^{\text {nd }}$ ed.), Cary, North Carolina, SAS Institute Inc., 210 p.

Snelder, T.H., and Lamourouz, N., 2010, Co-variation of fish assemblages, flow regimes and other habitat factors in French Rivers: Freshwater Biology, v. 55, p. 881-892 (Also available at $h t t p: / / d x . d o i . o r g / 10.1111 / j .1365-$ 2427.2009.02320.x).

Sparks, R.E., 1992, Risks of altering the hydrologic regime of large rivers, in Cairns, J., Niederlehner, B.R., and Orvos, D.R., ed., Predicting ecosystem risk: Vol XX. Advances in modern environmental toxicology: Princeton, NJ, Princeton Scientific Publishing Co., p. 119-152. 
Stanford, J.A., Ward, J.V., Liss, W.J., Frissell, C.A., and others, 1996, A general protocol for restoration of regulated rivers: Regulated Rivers Research and Management, v. 12, p. 391-414 (Also available at $h t t p: / / d x . d o i$. org/10.1002/(SICI) 1099-1646(199607)12:4/5<391::AIDRRR436>3.3.CO;2-W).

State of New New Jersey, 2007, New Jersey Pinelands Commission: accessed November 20, 2009, at http://www.state. nj.us/pinelands/cmp/summary.

Stribling, J.R., Moulton, S.R., and Lester, G.T., 2003, Determining the quality of taxonomic data: Journal of the North American Benthological Society, v. 22, p. 621-631 (Also available at $h t t p: / / d x$.doi.org/10.2307/1468357).

Townsend, C.R., Doldec, S., and Scarsbrook, M.R., 1997, Species traits in relation to temporal and spatial heterogeneity in streams: A test of habitat template theory: Freshwater Biology, v. 37, p. 367-397 (Also available at http://dx.doi. org/10.1046/j.1365-2427.1997.00166.x).

U.S. Environmental Protection Agency, 1997, Field and laboratory methods for macroinvertebrate and habitat assessment of low gradient, nontidal streams: Wheeling, WV, Mid-Atlantic Coastal Streams Workgroup, Environmental Services Division, Region 3, 23 p.

U.S. Environmental Protection Agency, 1997, Estimation and application of macroinvertebrate tolerance values: Washington, DC, National Center for Environmental Assessment, Office of Research and Development, EPA/600/P-04/116F, $80 \mathrm{p}$.

Vannote, R.L., Minshall, G.W., Cummins, K.W., Sedell, J.R., and Cushing, C.E., 1980, The river continuum concept: Canadian Journal of Fisheries and Aquatic Sciences, v. 37, p. 130-137 (Also available at http://dx.doi.org/doi:10.1139/ f80-017).

Van Sickle, J., 2003, Analyzing correlations between stream and watershed attributes: Journal of the American Water Resources Association, v. 39, p. 717-726 (Also available at http://dx.doi.org/10.1111/j.1752-1688.2003.tb03687.x).

Vieira, N.K.M., Poff, N.L., Carlisle, D.M., Moulton, S.R., II, Koski, M.L., and Kondratieff, B.C., 2006, A database of lotic invertebrate traits for North America: U.S. Geological Survey Data Series 187, (Also available at http://pubs.usgs. gov/ds/ds187/pdf/ds187.pdf.)
Walters, D.M., Leigh, D.S., Freeman, M.C., Freeman, B.J., and Pringle, C.M., 2003, Geomorphology and fish assemblages in a Piedmont river basin, U.S.A: Freshwater Biology, v. 48, p. 1950-1970 (Also available at $h t t p: / / d x . d o i$. org/10.1046/j.1365-2427.2003.01137.x).

Ward, J.V., 1992, Aquatic insect ecology: Biology and Habitat: New York, John Wiley and Sons, Inc., 438 p.

Ward, J.V., and Stanford, J.A., 1989, Riverine ecosystems: The influence of man on catchment dynamics and fish ecology: Canadian Special Publications in Fisheries and Aquatic Sciences, v. 106, p. 56-64 (Also available at http:// dx.doi.org/10.1002/rrr.3450080123).

Watson, K.M., Reiser, R.G., Nieswand, S.P., and Schopp, R.D., 2005, Streamflow characteristics and trends in New Jersey, water years 1897-2003: U.S. Geological Scientific Investigations Report 2005-5105, 131 p. (Also available at http://pubs.usgs.gov/sir/2005/5105/pdf/NJsir2005-5105_ report.pdf.)

Weisberg, S., 1985, Applied linear regression, (2d ed.): New York, John Wiley, 324 p.

White, B.T., Hoppe, H.L., Centinaro, G.L., Dudek, J.F., Painter, B.S., Protz, A.R., Reed, T.J., Shvanda, J.C., and Watson, A.F., 2006, Water resources data for New Jerseywater year 2005, v. 1. Surface-water data: U.S. Geological Survey Water-Data Report NJ-05-01, 386 p. (Also available at $h t t p: / / p u b s . u s g s . g o v / w d r / 2005 / w d r-n j-05-1 /$.)

Zampella, R.A., and Bunnell, J.F., 1998, Use of reference site fish assemblages to assess aquatic degradation in Pinelands streams: Ecological Applications, v. 8, p. 645-658 (Also available at $h t t p: / / d x . d o i . o r g / 10.1890 / 1051-$ 0761(1998)008[0645:UORSFA]2.0.CO;2).

Zampella, R.A., Procopio, N.A., Lathrop, R.G., and Dow, C.L., 2007, Relationship of land-use/land-cover patterns and surface-water quality in the Mullica River Basin: Journal of the American Water Resources Association, v. 43, p. 594-604 (Also available at $h t t p: / / d x . d o i . o r g / 10.1111 / j .1752-$ 1688.2007.00045.x).

Zapecza, O.S., 1989, Hydrogeologic framework of the New Jersey Coastal Plain: U.S. Geological Survey Professional Paper 1404-B, No. 24, 49 p. (Also available at $h t t p: / / p u b s$. er.usgs.gov/usgspubs/pp/pp1404B.) 
For additional information, write to:

Director, U.S. Geological Survey

New Jersey Water Science Center

810 Bear Tavern Road, Suite 206

West Trenton, NJ 08628

or visit our Web site at:

http://nj.usgs.gov/ 
